\title{
Novel Systems and Membrane Technologies for Carbon Capture
}

\author{
Eshorame Samuel Sanni $\mathbb{D}^{1},{ }^{1}$ Emmanuel Rotimi Sadiku $\mathbb{D}^{2}{ }^{2}$ \\ and Emeka Emmanuel Okoro (iD) ${ }^{3}$ \\ ${ }^{1}$ Department of Chemical Engineering, Covenant University, Ota, Ogun, Nigeria \\ ${ }^{2}$ Department of Materials, Chemical and Metallurgical Engineering, Tshwane University of Technology, Pretoria, South Africa \\ ${ }^{3}$ Department of Petroleum Engineering, Covenant University, Ota, Ogun, Nigeria
}

Correspondence should be addressed to Eshorame Samuel Sanni; adexz3000@yahoo.com

Received 6 October 2020; Revised 30 November 2020; Accepted 18 December 2020; Published 13 January 2021

Academic Editor: Sébastien Déon

Copyright (C) 2021 Eshorame Samuel Sanni et al. This is an open access article distributed under the Creative Commons Attribution License, which permits unrestricted use, distribution, and reproduction in any medium, provided the original work is properly cited.

Due to the global menace caused by carbon emissions from environmental, anthropogenic, and industrial processes, it has become expedient to consider the use of systems, with high trapping potentials for these carbon-based compounds. Several prior studies have considered the use of amines, activated carbon, and other solid adsorbents. Advances in carbon capture research have led to the use of ionic liquids, enzyme-based systems, microbial filters, membranes, and metal-organic frameworks in capturing $\mathrm{CO}_{2}$. Therefore, it is common knowledge that some of these systems have their lapses, which then informs the need to prioritize and optimize their synthetic routes for optimum efficiency. Some authors have also argued about the need to consider the use of hybrid systems, which offer several characteristics that in turn give synergistic effects/properties that are better compared to those of the individual components that make up the composites. For instance, some membranes are hydrophobic in nature, which makes them unsuitable for carbon capture operations; hence, it is necessary to consider modifying properties such as thermal stability, chemical stability, permeability, nature of the raw/starting material, thickness, durability, and surface area which can enhance the performance of these systems. In this review, previous and recent advances in carbon capture systems and sequestration technologies are discussed, while some recommendations and future prospects in innovative technologies are also highlighted.

\section{Introduction}

The continuous increase in gaseous emissions is a major environmental challenge that bedevils our planet as well as the global populace. Climate change and global warming are resultant effects of the release of $\mathrm{CO}_{2}, \mathrm{CH}_{4}$, chlorofluorocarbons (CFCs), $\mathrm{O}_{3}$, and NOx into the atmosphere $[1,2]$. The greenhouse gas contributions of chlorofluorocarbons/ methane are far higher than those of $\mathrm{CO}_{2}$ when compared on the basis of unit mass [2]. However, due to the release of $\mathrm{CO}_{2}$ from fossil fuels, which is the primary source (98\%) of the global energy demand, most of the efforts to combat the menace of greenhouse gases are concentrated on $\mathrm{CO}_{2}$ capture technologies [3]. In the year 2013, the high greenhouse gas concentrations in the earth's atmosphere were quite alarming; also, the $\mathrm{CO}_{2}$ concentration was $396 \mathrm{ppm}$ (i.e., about $142 \%$ of the estimated $\mathrm{CO}_{2}$ concentration in the preindustrial era [4]. Findings from the Global Atmosphere
Watch (a greenhouse gas bulletin) showed that $\mathrm{CO}_{2}$ concentration experienced the highest increase between 2012 and 2013, compared to those reported for previous years. However, this was judged to have been caused by the reduction in $\mathrm{CO}_{2}$ uptake in the biosphere. From 2013 to date, the increase in greenhouse gas emissions caused by a rapid rise in population density, industrial activities, and anthropogenic activities has given rise to unprecedented repercussions/effects ranging from environmental pollution to health deterioration, water contamination/pollution, ecodestruction, loss of aquatic life, and undesirable climate change. At a climate conference held in Paris (i.e., the COP21) in December 2015, a total of 195 countries instituted a resolution on the first-ever-historic legal-binding agreement on climate issues, where it was commonly agreed that the global temperature would be kept at an average increase of less than $2^{\circ} \mathrm{C}$, which is slightly above what was obtainable in preindustrial times. 
The resultant rise in the world's fossil fuel reserves alongside the rapid change in energy demands has led to the unavoidable global expansion of some existing plants, as well as the construction of new ones in order to boost production capacities as a preparatory measure to absorb the global energy shocks. This situation has extended into further years owing to the current state of industrial development and economic growth in different parts of the world, especially in the developed nations. According to the information provided by the Energy Information Administration (EIA), an arm of the US Department for Energy, while fossil fuels were projected to be the world's leading source of energy ( $80 \%$ of the world's energy) in the next two decades, energy consumption was predicted to also rise by $56 \%$ by 2040 . According to the literature, the $\mathrm{CO}_{2}$ emissions from power plants were predicted to rise by $46 \%$ in 2010 [5]. Furthermore, according to EIA reports, the combined $\mathrm{CO}_{2}$ emissions from India and China from the use of coal are expected to triple that of the US by the year 2030 [6].

Three strategies are employed in trapping $\mathrm{CO}_{2}$ emissions from fossil fuel-powered plants; the methods include oxy-, pre-, and post-combustion capture of $\mathrm{CO}_{2}$ [7]. In precombustion capture, the gas is trapped from the parent mixture prior to undergoing combustion. Oxy-combustion capture has to do with capturing $\mathrm{CO}_{2}$ during combustion, i.e., while burning gas in the air. In postcombustion capture, the gas is trapped from flue gas (a mixture of constituents such as nitrogen, water vapor, and oxygen), in a downstream unit retrofitted with a carbon capture system within the plant. The challenges associated with this process include low $\mathrm{CO}_{2}$ partial pressure, high flue gas temperature, and the high amount of $\mathrm{CO}_{2}$ in the flue gas $[7,8]$. This also confirms why coal-fired power plants have been reported to be one of the largest stationary point sources of $\mathrm{CO}_{2}$ emissions [9].

In the United States, policy implementation for $\mathrm{CO}_{2}$ reduction exists at the local and state levels [10]. However, requests to build new coal-fired power plants are being denied regularly due to their lack of $\mathrm{CO}_{2}$ controls at inception as well as their medium to high tolerance for $\mathrm{CO}_{2}$ emission [11]. In 2009, 44.5\% of US electricity was generated from coal, whereas, in 2008, $\mathrm{CO}_{2}$ emissions from electricity generation accounted for about 40 and $34 \%$ of the global anthropogenic and GHG emissions [12, 13]. Globally, $31.2 \mathrm{Gt} \mathrm{CO}_{2}$ emissions were told to have been released from fossil fuel combustion and cement production [14]; this value dropped by $1.3 \%$ in 2009 [15].

1.1. Some Related Reviews on Carbon Capture. In the study of Leung et al. [16], various aspects of carbon capture systems and some current state-of-the-art technologies for $\mathrm{CO}_{2}$ capture, transport, separation, storage, leakage phenomena, monitoring, and life cycle analysis were discussed. They asserted that the choice of a specific $\mathrm{CO}_{2}$ capture technology depends on the nature of the $\mathrm{CO}_{2}$-generating plant and fuel source. Based on their discussions, absorption is the most preferred method for capturing $\mathrm{CO}_{2}$ and according to them, it is due to the higher efficiency and cost-effectiveness of the process. Vakharia et al. [17] scaled up the performances of synthetic amine-doped thin-film composite membranes for $\mathrm{CO}_{2}$ capture from flue gas, where they recorded $\mathrm{CO}_{2}$ permeance $>700 \mathrm{GPU}\left(1 \mathrm{GPU}=10^{-6} \mathrm{~cm}^{3}(\mathrm{STP}) /\left(\mathrm{s} \mathrm{cm}^{2} \mathrm{cmHg}\right)\right)$ with corresponding $\mathrm{CO}_{2}$ selectivity above 140 at $330 \mathrm{~K}$. Aaron et al. [18] carried out a review of some existing $\mathrm{CO}_{2}$ capture technologies; they concluded that the most viable method for $\mathrm{CO}_{2}$ capture is absorption using MEA. Other liquid absorbents, i.e., piperazine and anionic liquids, have also been discussed as potential candidates for carbon capture [19]. However, piperazine which flows and reacts faster with $\mathrm{CO}_{2}$ than MEA has been proposed owing to its larger volatility relative to MEA; hence, its usefulness in $\mathrm{CO}_{2}$ absorption is quite expensive and which is the reason for its noncommercialization [20]. The review conducted by Brunetti et al. [21] compares $\mathrm{CO}_{2}$ separation involving membranes and other separation technologies, i.e., adsorption and cryogenic separation of $\mathrm{CO}_{2}$. They highlighted that membranes are strongly affected by low $\mathrm{CO}_{2}$ concentration and pressure from flue gas, which is a major hurdle in applying this technology.

Chemical absorption or scrubbing process is currently the technology most likely to be implemented in the near future but is rather energy-intensive. In recent years, membrane-based $\mathrm{CO}_{2}$ separation appears to be a competitive substitution for conventional chemical absorption technologies. Wang et al. [22] reviewed the basic process design techniques for some $\mathrm{CO}_{2}$ absorption processes using chemical solvents and membranes; they also highlighted the need to optimize some operational parameters, techniques for process modification, membrane module types, etc., in which the energy requirements and economic implications of both $\mathrm{CO}_{2}$ capture technologies were scrutinized. However, they asserted that membrane-based separation lacks obvious advantages, in terms of energy requirement and cost, over MEA-based absorption where $90 \% \mathrm{CO}_{2}$ capture is feasible.

Based on the review carried out on carbon capture and utilization (CCU) by Koytsoumpa et al. [23], commercial applications of the thermal power and industrial sectors of pre- and postcombustion captured carbon were discussed. The focus of CCU is for the trapped $\mathrm{CO}_{2}$ to serve as fuel or as a means of generating heat and power. Hence, they asserted that CCU combined with energy storage is an evolutionary approach for instilling the power to fuel concept, which in turn guarantees high market supplies of fuel and other chemicals. Furthermore, recent advances in supercritical $\mathrm{CO}_{2}$ cycles for heat and power production were also presented.

Owing to the different types of absorption, adsorption, membrane, and cryogenic processes available for carbon capture operations, absorption still stands out as the most widely used method in commercial applications. Based on the content and composition of treated gas samples, different physical and chemical methods of adsorption are available for carbon dioxide and sulfur species removal from process streams [24-27]. For mixtures containing low amounts of carbon dioxide, chemical solvents are preferred to physical solvents; however, physical solvents give better results at high partial pressures. In addition, the thermal energy 
requirement for gas separation processes involving chemical solvents is much higher compared to those of physical solvents due to the addition of heat via the reboiler attached to the stripper column [25]. This is because, according to Henry's law, the loading capacities of physical solvents have a virtual linear relationship with the partial pressures of the components to be removed, which in turn allows for easy solvent regeneration by pressure throttling. The dissolution of carbon dioxide in the physical liquid solvent is attributed to the van der Waals or electrostatic interaction and is optimal at high pressure and low temperature, hence the need to optimize the process conditions for optimum $\mathrm{CO}_{2}$ capture.

A review of the development of novel carbon capture technologies was conducted by Lockwood [28], where their energy requirements and cost implications were compared in terms of efficiency-penalty, cost of power, cost of the $\mathrm{CO}_{2}$ capture process, and the current developmental status of new technologies. For operations that actually factor in the cost of $\mathrm{CO}_{2}$ capture into the power generation process, chemical loop combustion or the oxyfuel-based Allam cycle offers great potentials to meet the economic requirements of the overall process. For retrofit designs, high performance is often associated with $\mathrm{CO}_{2}$ capture. According to them, in the US, the post-, pre-, and oxyfuel combustion research programmes present some ambitious targets for new technologies to achieve a $\mathrm{CO}_{2}$ capture cost of about $\$ 20$ per tonne. Novel solvents are seen to tilt towards lower-cost involvements in terms of energy regeneration requirements as compared to those associated with conventional amine solvents, phase-change systems, ionic liquids, other nonaqueous solvents, and enzyme-activation systems which are all promising technologies. Alternatively, other commercial gas separation technologies involving solid sorbents, membranes, and cryogenic separation have also been widely investigated. Although there are obvious cost implications for postcombustion capture applications, these techniques may offer some measurable benefits to precombustion capture systems, especially in areas where higher $\mathrm{CO}_{2}$ partial pressures are desired. Hence, the integration of the $\mathrm{CO}_{2}$ capture step and the water gas-shift reaction occurs within the adsorbents or membranes. In oxyfuel combustion, pressurised systems have shown a high tendency for efficiency improvements within the supercritical $\mathrm{CO}_{2}$ cycle at some unique conditions of combustion. Ceramic membranes for oxygen production were also recommended as a means of lowering costs relative to those obtained for cryogenic air separation. Dramatic energy saving can also be achieved via chemical looping strategies, as a result of the inherent avoidance of the possibility of a gas separation step. This technology offers significant scale-up options to companies and research institutes, where the focus is on lowcost oxygen carriers. Raza et al. [29] reviewed the various processes involved in the reduction of $\mathrm{CO}_{2}$ emissions where it was mentioned that carbon capture and storage techniques hold high promises for reducing the global carbon footprint. Their thought pattern focused on a CCS technology that deals with the capture and storage of $\mathrm{CO}_{2}$ in deep geological formations for the regulation of the earth's temperature.
Some basic guidelines/principles for long-term $\mathrm{CO}_{2}$ sequestration and storage were also discussed with considerations for the processes and mechanisms (buoyancy, pressure gradient, reservoir heterogeneity, dispersion, diffusion, mineralization, phase trapping, and adsorption by organic materials) involved alongside the various interactions stimulated by supercritical $\mathrm{CO}_{2}$ injection into the subsurface of geological sites. According to the authors, the selection of apt geological sites for $\mathrm{CO}_{2}$ storage is informed by the physical characteristics of $\mathrm{CO}_{2}$ and its phase change tendencies as influenced by $\mathrm{CO}_{2}$ transport/hydraulic pressure and temperature variation. Although $\mathrm{CO}_{2}$ can exist as liquid, solid, or gas, it often exists as a supercritical fluid at geological formations whose depths are greater than $800 \mathrm{~m}$ and this is as a result of an increase in pressure and temperature at such depth $[30,31]$. According to the review conducted by Sood and Vyas [32], $\mathrm{CO}_{2}$ can be trapped from process facilities and transported to sedimentary basins, saline aquifers, and coal reservoirs for storage. The basic techniques highlighted include oxy-, pre-, and postcombustion strategies. Based on the storage capacities of the CCS technique, it is obvious that the storage capacities of CCS systems make them the most prospective candidates for carbon capture and storage owing to the huge tons of $\mathrm{CO}_{2}$ storage capacities of the aforementioned sites. However, issues that bother on safety are paramount, especially when these sites are overburdened by excessive pressures that may subsequently result in hazards.

Despite all the efforts put into the well-appreciated past reviews as highlighted in some of the documented literature, it is evident that none seems to have looked into the collection of research works that have do with the application of hybrid systems/novel solvent systems and membrane technologies as the best potential candidates for carbon capture in lieu of the excellent properties they offer in those combinations. This then served as one of the major motivators for this study. Others include the scarcity of literature on the capture of several other carbonaceous compounds and the ill conceptualization of carbon capture in the light of $\mathrm{CO}_{2}$ capture only.

To date, a lot of attention has been given to $\mathrm{CO}_{2}$ capture due to its very high concentration in the earth's atmosphere relative to other gases; this has also led to the minimal attention received by other greenhouse gases, hence another motivation for this research, which serves to advocate for the focus on hybrid technologies for the trapping of $\mathrm{CO}_{2}$ and other carbonaceous substances rather than paying attention to $\mathrm{CO}_{2}$ only. Also, researchers are still searching for better strategies for curbing the global carbon footprint by trying out new measures that are not only highly efficient but also cost-effective and environmentally friendly. This is because, while a lot of the existing techniques are targeted at $\mathrm{CO}_{2}$ capture, a myriad of these techniques lack high $\mathrm{CO}_{2} /$ carbon selectivity, stability, durability, etc. Hence, this paper seeks to uncover some of the advances made in carbon capture research, as well as consider possible ways of improving on the current technologies, all aimed at optimizing their performances towards ensuring a clean environment. Although somewhat efficient, the known/aforementioned $\mathrm{CO}_{2}$ capture 
technologies are quite expensive, thus giving an estimate of about $70-80 \%$ of the overall cost of a full CCS system, capture, transport, and storage [33]. Therefore, significant R\&D efforts are currently focused on the reduction of operating costs and energy penalties which must be borne out of strategic selection of the choice materials, such as hybrid technologies, without a compromise for low quality while optimizing the process conditions towards ensuring high carbon selectivity and separation. All of these alongside discourses on the use of modified hybrid systems/MOFionic liquid systems for multigas $\left(\mathrm{CCl}_{3}, \mathrm{CCl}_{4}, \mathrm{CH}_{4}, \mathrm{H}_{2} \mathrm{Cl}_{2}\right.$, CFCs, etc.) capturing are barely available with major attention given to conventional absorption/adsorption processes alongside oxy, pre-, and postcombustion capture processes for $\mathrm{CO}_{2}$ sequestration because the term carbon capture is often seen to be limited to $\mathrm{CO}_{2} / \mathrm{CH}_{4}$ capture as evidenced by the available literature. Also, any carefree attitude in this regard/the neglect of other greenhouse gases will gradually result in the accumulation/build-up of these gases to the point that they begin to constitute serious problems.

1.2. Categories of Carbon Sequestration Technologies. The existing carbon capture technologies can be grouped into the following categories.

\subsubsection{Physiochemical Absorption}

(1) Physical Absorption: Selexol, Rectisol, Fluorinated Solvents, and Ionic Liquids. Physical absorption involves the reversible/nonreversible use of solvents that have high affinity for carbonaceous substances; these solvents include methanol, propylene carbonate, dimethyl ethers of polyethylene glycol, fluorinated solvents, and the most recent group known as ionic liquids. Ionic liquids (ILs) are liquid salts of cations and anions; they have boiling points of less than $100^{\circ} \mathrm{C}$ and have the ability to trap $\mathrm{CO}_{2}$ from a mixture of gases [34-36] owing to their inherent properties, such as low volatility, high $\mathrm{CO}_{2}$ solubility, thermal stability, and their susceptibility to structural tuning that allows for the attainment of certain advantageous properties [37-39]. Several studies involving ILs have been devoted to determining the extent of $\mathrm{CO}_{2}$ solubility, selectivity and IL performance, as well as their thermal/chemical stability $[34,40]$. Some advances on the use of amine-modified ILs or task-specific ILs (TSILs) [41, 42] have shown that these liquids have high affinity for $\mathrm{CO}_{2}$. Although the literature has recorded some significant advances in the production of low-viscosity ILs, one common challenge associated with the use of TSILs/ILs is the high viscosity of the fluids after $\mathrm{CO}_{2}$ entrainment during gas separation processes. Another solvent trapping process for $\mathrm{CO}_{2}$ capture is the Rectisol process. The Rectisol process (Figure 1) uses cold methanol to trap acid gases such as $\mathrm{CO}_{2}$ from contaminated gas streams [43-45]. The Fluor process employs propylene carbonate $\left(\mathrm{C}_{4} \mathrm{H}_{6} \mathrm{O}_{3}\right)$ and $\mathrm{CO}_{2}$ partial pressure for removing $\mathrm{CO}_{2}$, while the Selexol process makes use of dimethyl ethers of polyethylene glycol in trapping $\mathrm{CO}_{2}$ at pressures ranging from 2.07 to $13.8 \mathrm{MPa}$.

The use of Purisol, Rectisol, Selexol, etc., is common in the oil and gas industry, and they are often preferred over chemical solvents at high acid gas partial pressures. Choosing the right solvent for natural gas sweetening seriously depends on factors such as gas composition, temperature, and partial pressure of gas, as well as the product specs. The works of Tennyson and Schaaf [46] and Kohl and Nielsen [45] are recommended for due consultation by readers. Over a wide range of conditions, aqueous amines are suitable for acid gas absorption from natural gas; however, these solvents still have some serious shortcomings, which include high energy costs for solvent regeneration [47], low $\mathrm{CO}_{2} / \mathrm{H}_{2} \mathrm{~S}$ selectivity, corrosivity, and high volatility. This, however, sparked off the need for other viable alternatives which in turn ushered in the era of ionic liquids. Considering the past few decades, a huge chunk of studies have discussed the solubility of $\mathrm{CO}_{2}$ relative to other acid gases in several ionic liquids [34, 48]. However, evidence has shown that, for high gas absorptivity of $\mathrm{CO}_{2}$ in ILs, $\mathrm{CO}_{2}$ solubility is trivial relative to the selectivity because the latter gives more credence to the degree of separation obtained from an absorption process [48]. In clear terms, considering the opinions of experts, despite the essentiality of both parameters, $\mathrm{CO}_{2}$ selectivity is more dependable relative to its influence on the absorptivity of ILs. In another study, $\mathrm{CO}_{2}$ absorption-desorption rates in polyionic liquids (hybrid system) were reported to be much faster compared to those of ionic liquids and the processes are totally reversible [49-51]. The absorptive potentials of ionic liquids, monomeric and polymeric materials, rely on the chemical and molecular structure of the ions/anions that make up the polar ends of the liquids [50]. Generally, ILs are characterized by low vapor pressures, nonflammability, chemical/ thermal stability, tunable polarity, reliable electrolytic properties, and easy recycling [52].

A method to determine the bubble-point pressures of $\mathrm{CO}_{2}$ and $\mathrm{CH}_{4}$ at temperatures of 303.15 and $363.15 \mathrm{~K}$ and at pressures up to $14 \mathrm{MPa}$ using the Peng-Robinson Equation of state and the van der Waal's mixing rule, in ionic liquids, was established by Ramdin et al. [53]. The solubility of $\mathrm{CH}_{4}$ was estimated to be 10 times lower than that of $\mathrm{CO}_{2}$ on a mole fraction basis. Furthermore, Henry's constants for $\mathrm{CO}_{2}$ and $\mathrm{CH}_{4}$ for all the ionic liquids (ILs) were used to determine the ideal $\mathrm{CO}_{2} / \mathrm{CH}_{4}$ selectivities which gave values comparable to those obtained for the Selexol, Purisol, Rectisol, Fluor, and sulfonate solvents. The estimated $\mathrm{CO}_{2} / \mathrm{CH}_{4}$ selectivity decreased at increased temperature and molecular weight. Genduso and Pinnau [54] also carried out a study that deals with the estimation of the sorption, diffusion, and plasticization properties of cellulose triacetate polymer films in a mixed-gas $\left(\mathrm{CO}_{2} / \mathrm{CH}_{4}\right)$ environment.

(2) Chemical Absorption: Methanol Amine (MEA), Caustic Alkali, and $\mathrm{NH}_{3}$. The Warrior Run coal-fired power station in the United States has a $\mathrm{CO}_{2}$ capture capacity of about $150 \mathrm{t} / \mathrm{d}$. Amongst the choice solvents for $\mathrm{CO}_{2}$ capture, MEA is the most widely used amine amongst other members of 


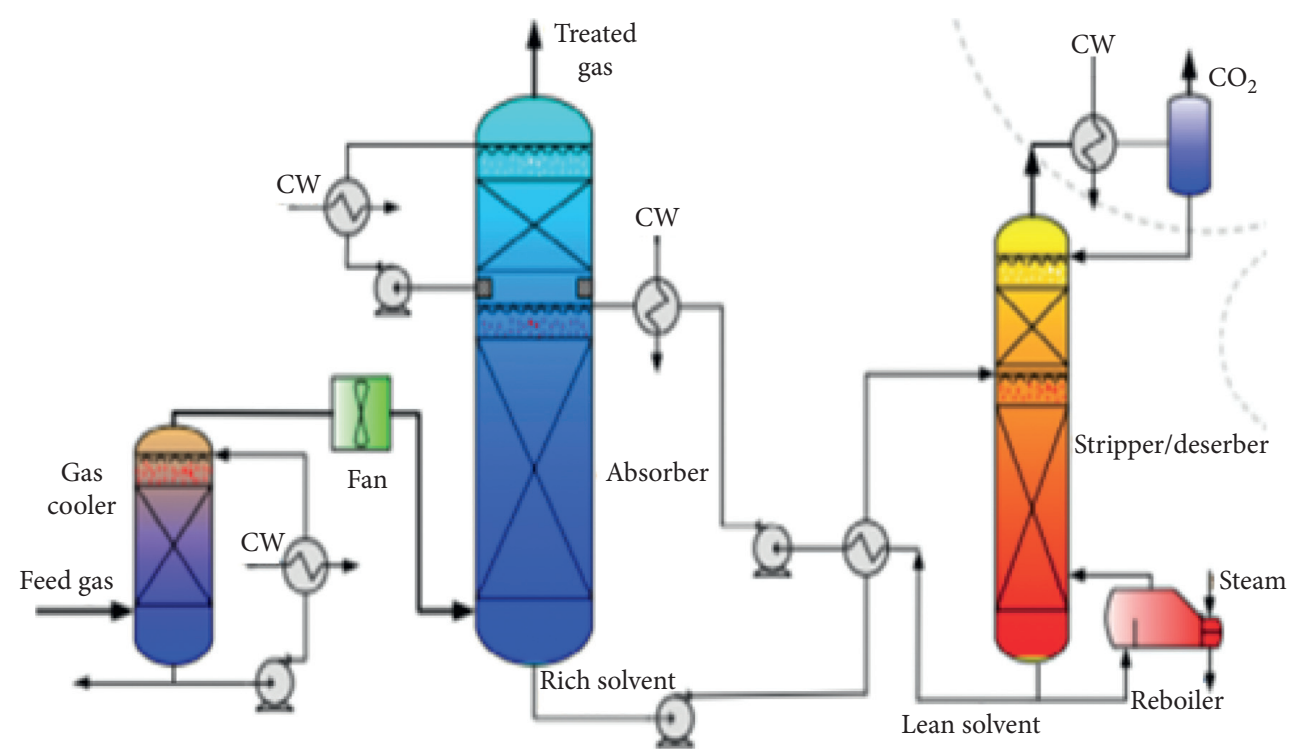

Figure 1: The Rectisol process for gas treatment (reprinted from Sanni et al. [27] and Salako et al. [43]).

the amine family because the $\mathrm{CO}_{2}$ recovery rate and product purity are as high as $98 \%$ and $99 \%$, respectively. However, one major demerit of this method is the tendency for MEA degradation when it is in contact with the oxidising environment of flue gas, whereas the energy requirement for the regeneration of the spent solvents can reduce energy costs by about $40 \%$ when compared with the cost incurred from using conventional MEA solvents. Hence, alternative solvents such as sterically hindered amines have been proven to possess good absorption and desorption features with minimal degradation or low solvent loss during carbon sequestration [27].

Till date, the most widely adopted technique for $\mathrm{CO}_{2}$ capture from postcombustion processes/flue gas involves the use of aqueous solvents such as (MEA), diethanolamine (DEA), and methyl diethanolamine (MDEA) as well as hybrid systems which comprise of a mixture of more than one amine [55-57] or blends of amines and chemical solvents such as $\mathrm{Ca}(\mathrm{OH})_{2}$ (Figure 2). Gas scrubbing, using alkanol amines, is one of the most widely adopted costeffective strategies available on commercial scale for postcombustion $\mathrm{CO}_{2}$ capture [58].

In order to overcome the limitations posed by aminebased solvents for stripping $\mathrm{CO}_{2}$ from flue gas, they can (i) be doped with $0.1 \mathrm{M} \mathrm{Ca}(\mathrm{OH})_{2}+27.3-30 \%$ DEA at pressures of 2-2.7 bar for optimum $\mathrm{CO}_{2}$ capture of about $98.3-99.6 \%$ (Figure 3) or (ii) be replaced with aqueous ammonia for $\mathrm{CO}_{2}$ separation owing to its inherent lower heat of absorption. In addition, liquid ammonia $\left(\mathrm{NH}_{4} \mathrm{OH}\right)$ is known to be able to trap impurities such as NO and SOx that are present in the gas stream. However, one major setback associated with the use of ammonia-based solvents is the recurring need of lowering the flue gas temperature prior to it being introduced in to the absorption column; this helps to abate the ammonia losses that would have ensued if the flue gas was introduced into the absorption column at higher temperature. High gas temperature increases the energy requirement of a large volume of flue gas that is yet to be treated [59]. Another limitation associated with the use of liquified ammonia for $\mathrm{CO}_{2}$ capture is that the chilled ammonia may foul heat exchangers as a result of the deposition of ammonium bicarbonate from saturated liquids [7].

1.2.2. Cryogenic Separation. Cryogenic separation of $\mathrm{CO}_{2}$ from a gaseous mixture is done via simultaneous cooling and condensation. Cryogenic separation is commercially adopted for streams with $>90 \% \mathrm{CO}_{2}$ concentrations; however, the process is not economical for more dilute $\mathrm{CO}_{2}$ streams. One major limitation of cryogenic separation of $\mathrm{CO}_{2}$ is the amount of energy required to enforce refrigeration, especially for dilute streams. Also, dehydration of the gaseous stream is a necessary step prior to cooling because it helps to prevent plugging/blockages. In lieu of the aforementioned limitations, cryogenic separation of $\mathrm{CO}_{2}$ engenders the production of liquid $\mathrm{CO}_{2}$ as a transport fuel for ships [60]. Cryogenic operations are often compatible with highly pressured/concentrated gaseous mixtures, such as in precombustion or oxygen-fired combustion processes.

To date, cryogenic sequestration of $\mathrm{CO}_{2}$ is deemed unrealistic owing to the high cooling costs incurred from the process; hence, there is a need for new developments/ methods for cutting down the huge costs associated with cooling the gas. The work of Knapik et al. [61] suggests that the cold duty for a $\mathrm{CO}_{2}$ separation protocol must come from an integrated liquefied natural gas (LNG) regasification or cryogenic air separation system, which takes advantage of an attached $\mathrm{CO}_{2}$ liquefaction and separation module that helps to ensure the efficient denitrification of natural gas towards ensuring low energy consumption. Natural gas denitrification is a subject that is poorly addressed by the current body of literature; this then flags the extent of the urgency of research works that qualitatively address the subject matter. According to Knapik et al. 


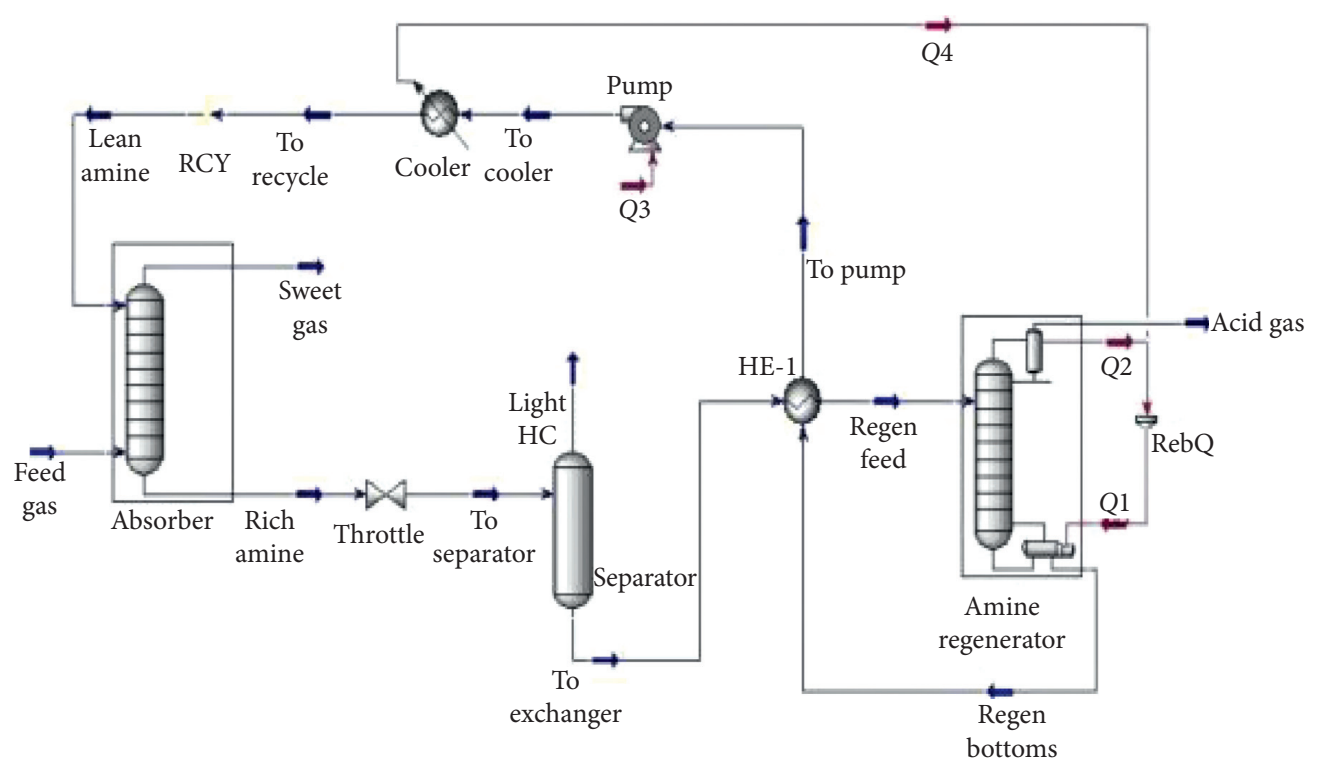

FIgUre 2: Process flow diagram for a DEA-Ca(OH) $)_{2}$ gas scrubbing plant (adapted from Sanni et al. [27]).

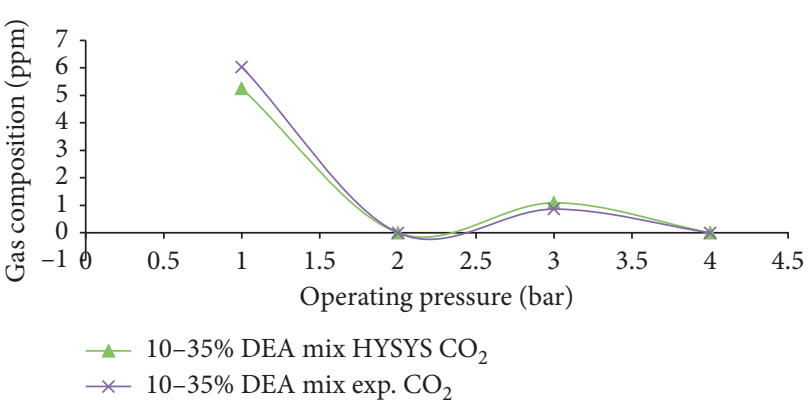

FIGURE 3: Operating pressure vs. $\mathrm{CO}_{2}$ absorption using $0.1 \mathrm{M}$ $\mathrm{Ca}(\mathrm{OH})_{2}+10-35 \%$ DEA (adapted from Sanni et al. [27]).

[61], the cryogenic separation of $\mathrm{CO}_{2}$ considers the separation of liquid $\mathrm{CO}_{2}$ from flue gas generated from oxy-fuel combustion. The outlet $\mathrm{N}_{2}$ stream transiting from an $\mathrm{N}_{2}$ removal unit (NRU) serves as the cold stream from the condenser that helps to liquefy $\mathrm{CO}_{2}$. As a result of the low temperature generated from nitrogen expansion, the inclusion of an external refrigeration cycle is not required, and this makes the process somewhat economical. The amount of trapped $\mathrm{CO}_{2}$ from the process is a function of the flue gas composition and operating pressure. Based on their findings, $83.07 \% \mathrm{CO}_{2}$ of $99.17 \%$ purity can be captured in this process. The energy required for separating the liquified $\mathrm{CO}_{2}$ is $0.125 \mathrm{kWh} / \mathrm{kg} \mathrm{CO}_{2}$ or $449 \mathrm{~kJ} / \mathrm{kg} \mathrm{CO}_{2}$. This novel $\mathrm{CO}_{2}$ separation unit offers a unique opportunity to produce liquified $\mathrm{CO}_{2}$ at moderate conditions; the integration of both cryogenic processes is technically and economically advantageous. Xu and Lin [62] successfully carried out the cryogenic separation of $\mathrm{CO}_{2}$ from flue gas generated from natural gas. They asserted that the hybrid NRU- $\mathrm{CO}_{2}$ capture installation is an innovative concept with good commercialization potential. The optimization of a cascaded thermodynamic system for separating $\mathrm{CO}_{2}$ from liquified natural gas has been investigated [63], while the effect of multiple cryogenic desublimation on the dehydration and decarbonization of natural gas was studied by Ali et al. [64]. Song et al. [65] carried out a study that bothers on the cryogenic separation of $\mathrm{CO}_{2}$ on Stirling coolers via heat integration.

1.2.3. Membrane Separation/Absorption. The performance of membranes for carbon capture processes is measured by the ease with which the component of interest adsorbs onto the surface of the membranes whilst allowing the permeation of other components. Membrane types include porous inorganic membranes, palladium-based, ceramic, polypropylene, polyphenylene oxide/polydimethylsiloxane (for gas separation), polymeric, zeolite, and MOF membranes, which cannot give high degrees of separation, and thus would require the integration of multiple stages and/or recycle streams. In lieu of this, problems such as process complications, energy consumption, and high costs often arise. Hence, solvent-assisted membranes are being developed to combine the best features of membranes and solvent scrubbing. Much development is required before membranes could be used on a large scale for carbon capture in power stations [44].

Polymeric membranes (Figure 4(a)) are classified as dense membranes which include polyimides, polysulfones, and cellulose acetate as well as their derivatives. Another group is one that comprises fixed-site carriers (FSC) (Figure 4(b)); they are made by coating polyvinyl amine on several supports. These membranes ensure high $\mathrm{CO}_{2}$ selectivity and gas permeation/rejection by means of an integrated carrier within the membrane. The third group includes membranes fused with low-vapour-pressure liquids (e.g., $\mathrm{K}_{2} \mathrm{CO}_{3}$ or diethanolamine) as supports for housing the immobilized carrier within the membrane pores (Figure 4(c)). The three mechanisms (diffusion, sieving, and 


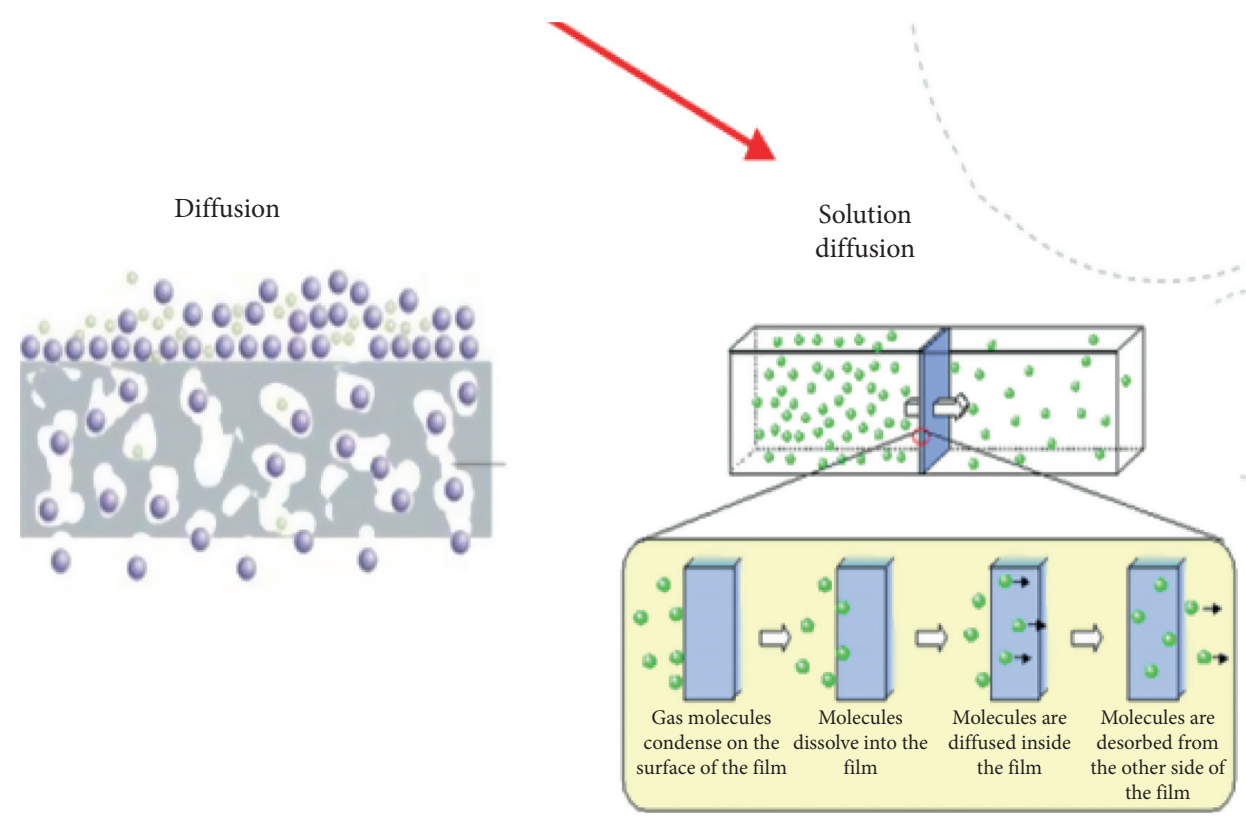

(a)

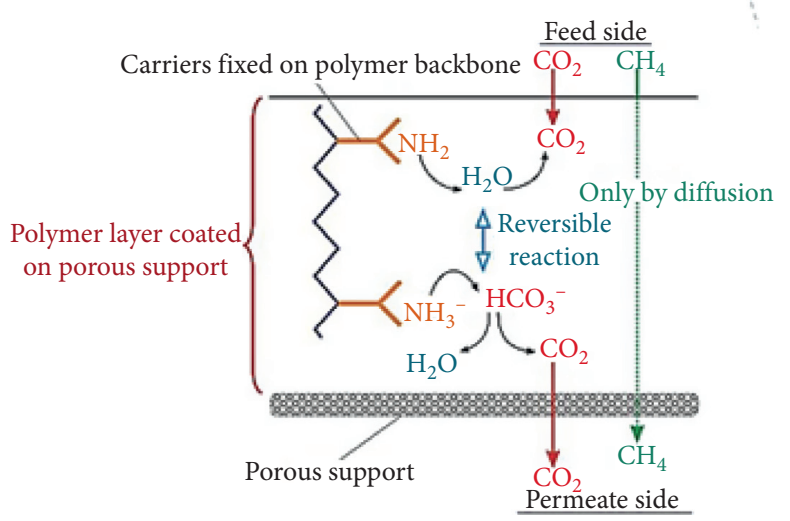

(b)

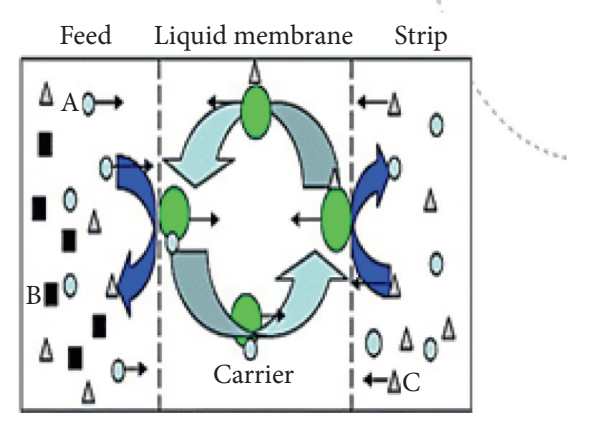

(c)

Figure 4: Schematic view of (a) dense polymeric membrane, (b) fixed-site carrier membrane, and (c) supported liquid membranes (adapted from Bolland [44]).

solution diffusion) responsible for gas adsorption in polymeric membranes are as illustrated in Figure 5.

In the study carried out by Tan et al. [66], a flexible microporous organic polymer (MOP) tagged BOP-1 was synthesized and functionalized using $\mathrm{Cl}$ and $\mathrm{NH}_{2}$ moieties. Their findings revealed higher $\mathrm{CO}_{2}$ uptake within a pressure limit of 1 bar, thus giving $\mathrm{CO}_{2}$-trapped concentrations of 3.94 and $1.60 \mathrm{mmol} / \mathrm{g}$ at 273 and $298 \mathrm{~K}$, respectively. At $273 \mathrm{~K}$, the polymer selectivity for $\mathrm{CO}_{2} / \mathrm{CH}_{4}$ was abrupt, i.e., 568 at 0.02 bar. Considering the experimental and theoretical validations, they asserted that the $-\mathrm{CH}_{2}-\mathrm{NH}$ - linker within the polymer framework played a significant role in enhancing $\mathrm{CO}_{2}$ polymer binding and was thus responsible for the flexibility of the entire framework. Amongst the diverse $\mathrm{CO}_{2} / \mathrm{CH}_{4}$ sequestration technologies, porous materials are very ideal candidates owing to their high energy efficiencies and low operating costs [67].

For MOFs, some major limitations in their use include the high energy requirement of the solvent regeneration process, thermal stability of the amine system during regeneration, and the presence of impurities that are present in the flue gas stream, which may have some significant effect on the chemical stability and sorption capacity/potential of the solvent $[68,69]$. MOFs are a class of porous materials comprising of a network of metal ions/clusters of nodes connected by organic ligands; they have a wide application in gas separation processes $[70,71]$. These materials have very high surface areas, ultrahigh porosity, and flexibility, which is imposed by the presence of ligands/connectors [70, 72-78]. One major merit of MOFs over other solid adsorbents lies in their adaptability to pore size tuning and framework functionalization, which are premeditated by carefully selecting suitable ligands, functionality/surface enhancers, metal ions, and the mode of activation. The limitations of MOFs are more pronounced in humid environments and this has led to a probe into understanding their mechanisms of operation during gas adsorption, which has further stimulated the development/integration of novel 


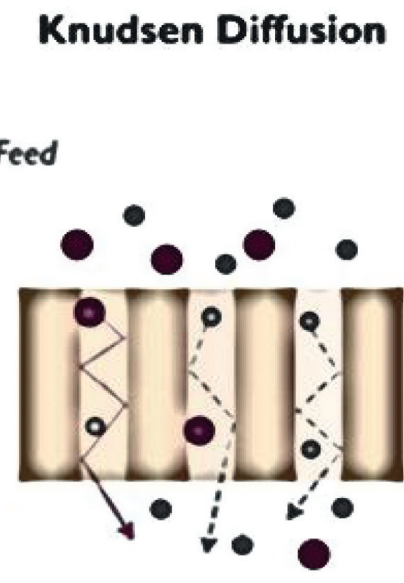

Permeote

ocoustac

\section{$\cdot$} Molecular Sieving $\overrightarrow{\text { Retentote fow }}$
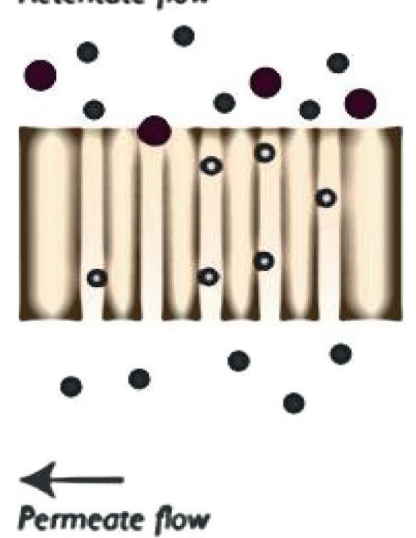

Size exclusion

\section{Solution-diffusion}

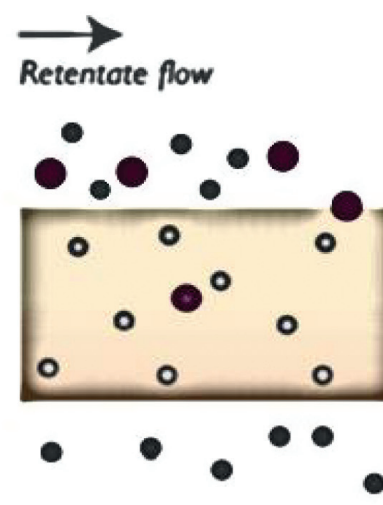

Permeote flow

Solubility diference

FIGURE 5: Mechanism of diffusion of gas through membrane pores (adapted from Bolland [44]).

structures, hybrid systems, and technologies as means of improving their adaptation to such environments. The strategies adopted in improving the performance of MOFs include the following.

(1) The Opening up of Metal Sites. This involves the removal of solvent molecules connected to metal nodes by the creation of a vacuum or application of heat after synthesizing the metal framework during chemical activation. The presence of open metal sites in MOFs impacts their $\mathrm{CO}_{2}$ selectivity and the binding energy between adsorbed $\mathrm{CO}_{2}$ molecules and the MOF surface. This helps to open metal centers/binding sites where $\mathrm{CO}_{2}$ molecules can become attached and bind the pore surface via dipole-quadrupole interactions. A method that helps gain insight into the interactions between trapped $\mathrm{CO}_{2}$ and the ionic force field generated by open metal sites in MOF-74 has been developed. The procedure adopted allows for the accurate estimation of the adsorption isotherms that enhance the subsequent evaluation of the hypothetical open metal sites in MOFs [79]; the findings corroborate the results of Kong et al. [80]. Some widely used MOFs include HKUST-1, M-MIL100, M-MIL-101, and M-MOF-74, where M represents the metal site. In order to accurately determine the influence of open metal sites in MOFs, it is expedient to isolate the effects contributed by the organic ligand, the synthetic route, and the nature of the inherent functional groups present in the MOF framework. For M-MOF-74 subjected to low pressures, some authors have confirmed the suitability of light metal sites for its surface area enhancement alongside its $\mathrm{CO}_{2}$ uptake [81]. An examination of the effect of metal centers in M-MOFs was done using a computational approach [81-83] that portrays $\mathrm{Rh}, \mathrm{Pd}$, Os, Ir, and Pt as ideal candidates for enhancing $\mathrm{CO}_{2}$ capture within MOFs. Casey et al. [84] carried out an investigation on the adsorption mechanism and electrostatic force field created by metal centers comprising of $\mathrm{Mo}, \mathrm{Ni}, \mathrm{Zn}, \mathrm{Fe}, \mathrm{Cu}$, and $\mathrm{Cr}$ in the isomers of HKUST-1. They observed that divalent metals such as $\mathrm{Mg}^{2+}$ helped to improve the binding potential of $\mathrm{CO}_{2}$ which in turn enhanced $\mathrm{CO}_{2}$ selectivity. It was also observed that the mode of activation of the metal matrix also influenced the MOF's affinity for $\mathrm{CO}_{2}$; their results also support the findings in the work of Llewellyn et al. [85], in which they confirmed the effect of different activation methods on $\mathrm{CO}_{2}$ loading using MIL-100 and MIL-101. The interaction of $\mathrm{CO}_{2}$ and unsaturated $\mathrm{Cr}(\mathrm{III}), \mathrm{V}$ (III), and $\mathrm{Sc}$ (III) metal sites in MIL-100 framework was studied using variable-temperature infrared spectroscopy. The estimated adsorption enthalpies for $\mathrm{Cr}$ (III), $\mathrm{V}(\mathrm{III})$, and $\mathrm{Sc}(\mathrm{III})$ were $-63,-54$, and $-48 \mathrm{~kJ} /$ mol, respectively; these are the highest ever-recorded $\mathrm{CO}_{2}$ adsorption enthalpies on MOFs with open metal centers [86]. The work of Sumboon et al. [87] involves the synthetic characterization of $\mathrm{M}-\mathrm{DABCO}$ metal series $(\mathrm{M}=\mathrm{Ni}, \mathrm{Co}, \mathrm{Cu}$, and $\mathrm{Zn}$ ), in which they systematically tested the effect of different metal centers on surface area, pore volume, and $\mathrm{CO}_{2}$ uptake. They asserted that, of all the tested metals, NiDABCO possessed the highest pore volume and specific surface area as a result of the high charge density concentration at the metal center. A close comparison of the M-DABCO with MIL-100(Cr) and an activated carbon (AC) sample showed that the presence of the unsaturated cations gave $\mathrm{CO}_{2}$ uptake of $180 \mathrm{~cm}^{3} / \mathrm{g}$ as compared to the values obtained for the $\mathrm{Cr}$ and AC samples which are $60 \mathrm{~cm}^{3} / \mathrm{g}$ and $30 \mathrm{~cm}^{3} / \mathrm{g}$, respectively [88].

(2) Presynthetic Modification of Organic Ligands. Organic ligands/linkers are the functional bridges that help connect a network of metal nodes; hence, they are responsible for the final outlook of the framework structure, pore volume/pore window, and surface area, which are highly essential for the successful sequestration of $\mathrm{CO}_{2}$. Ligand functionalization infuses some active functional groups into MOFs which 
subsequently ease the organic ligand modification by the inducement of strong covalent interactions. Torrissi et al. [89] modelled the impact of some functional groups attached to ligands using the density functional theory (DFT). The inclusion of amine functional moieties in organic ligands has also been proven to have positive effects on open nitrogen sites within MOF frameworks [90]. The work of Keceli et al. [91] bothers on an amide modification of four biphenyl ligands. However, it was observed that varying the length of the alkyl amide group had a significant impact on the porosity, surface area, and $\mathrm{CO}_{2}$ containment of the MOF. The activation procedure was also found to have influenced the surface area of the MOF, which was allotted to have been caused by solvent removal from the MOF framework. Yang et al. [92] synthesized three amino-functionalized MOFs from 2-aminoterephthalate (ABDC), $\mathrm{Mg}, \mathrm{Co}$, and $\mathrm{Sr}$. The produced MOFs had low surface areas of 63,71 , and $2.5 \mathrm{~m}^{2} / \mathrm{g}$ for $\mathrm{Mg}, \mathrm{Co}$, and $\mathrm{Sr}$, respectively, which also culminated in low $\mathrm{CO}_{2}$ uptake of about $1.4 \mathrm{mmol} / \mathrm{g}$ at 1 bar and $298 \mathrm{~K}$. However, the MOFs demonstrated high selectivities for $\mathrm{CO}_{2}$ with the highest being 396 as recorded for the Mg-ABDC, which also corresponds to a high heat of adsorption [92]. Shimizu et al. [93] made use of 3-amino-1,2,4-triazole ligands in designing a 3D MOF structure of characteristic area, pore volume, and $\mathrm{CO}_{2}$ uptake of $782 \mathrm{~m}^{2} / \mathrm{g}, 0.19 \mathrm{~cm}^{3} / \mathrm{g}$, and $4.35 \mathrm{mmol} / \mathrm{g}$, respectively, at $1.2 \mathrm{bar}$ and $273 \mathrm{~K}$. Furthermore, the estimated enthalpy of adsorption of the $\mathrm{Mg}$ ABDC was $40.8 \mathrm{~kJ} / \mathrm{mol}$ at zero coverage, which is very close to the value $(48.2 \mathrm{~kJ} / \mathrm{mol})$ obtained for a commercial zeolite ( $\mathrm{NaX}$ ) sample. Xiong et al. [94] employed nitrogen atoms and methyl functional groups supported on 5-methyl-1Htetrazole ligands in synthesizing UTSA-49 framework. The synthesized MOF gave a $\mathrm{CO}_{2}$ uptake and enthalpy of 13.6 wt. $\%$ at $1 \mathrm{bar}, 298 \mathrm{~K}$, and $27 \mathrm{~kJ} / \mathrm{mol}$, respectively. The results obtained from testing the effects of the triazolate ligands were found to be in close agreement with the findings of Gao et al. [95]. Hence, it becomes very pertinent to gain good insight into the mechanisms behind the synergistic effects offered by the pore-surface-imposed functional groups as well as their size exclusion effects owing to their potential in optimizing the performance of functionalized MOFs.

(3) Postsynthetic Functionalization of MOF-Metal Matrices. Postfunctionalization of MOFs helps guide against the limitations imposed by presynthetic functionalization. However, an accurate control of the process conditions is required, which is aimed at retaining the service life and stabilities of the unstable functional groups during solvothermal synthesis. In addition, the infusion of other functional groups into the synthetic mix may result in the distortion of the metal framework as a result of the improper mixing and steric hindrance that occur during crystallization, thus yielding undesired products. The insertion of functional groups at metal sites at the presynthetic stage of the framework casting may adversely affect the building blocks of the MOF, which may in turn lead to the structural deformation of the crystal lattice of the MOF [96-98]; hence, postsynthetic functionalization is considered a viable approach for combatting the highlighted shortcomings towards capacitating the resulting MOFs for high carbon/ $\mathrm{CO}_{2}$ capture. Some amine-moiety-modified solid adsorbents [99-102] and MOFs $[103,104]$ have shown improved $\mathrm{CO}_{2}$ sorption over their unmodified counterparts. Lee et al. [105] grafted 16.7 wt.\% diamine into MOF-74/Mg(dopbdc) at room temperature. The modified $\mathrm{MOF}$ exhibited a $\mathrm{CO}_{2}$ uptake of 13.7 wt.\% at 0.15 bar, while McDonald et al. [106] reported a $\mathrm{CO}_{2}$ uptake of $12.1 \mathrm{wt} \%$ for $\mathrm{N}, \mathrm{N}^{\prime}$-dimethyl ethylenediamine grafted into $\mathrm{Mg}$ (dopbdc). The isosteric enthalpy of adsorption of $\mathrm{CO}_{2}$ ranged from 49 to $51 \mathrm{~kJ} / \mathrm{mol}$, thus confirming chemisorption of $\mathrm{CO}_{2}$ molecules, whose kinetics was determined by the formation of carbamic acid as identified using the Fourier transform infrared (FTIR) spectroscopy. The multicycle adsorption evaluation of the engrafted $\mathrm{Mg}$ (dopbdc) only revealed a 3\% loss of $\mathrm{CO}_{2}$ uptake after the $5^{\text {th }}$ cycle; however, the MOF was found to be hydrologically stable with a high $\mathrm{CO}_{2}$ uptake. The work of Chernikova et al. [107] bothers on the synthesis of a nanoporous fluorinated MOF named "SIFSIX-3-M," where $\mathrm{M}=\mathrm{Zn}$, $\mathrm{Cu}$, or $\mathrm{Ni}$, which encompasses a periodic arrangement of fluorine moieties in an enclosed one-dimensional (1D) channel; the synthesized MOF was seen to have a remarkable $\mathrm{CO}_{2}$ selectivity over $\mathrm{CH}_{4}$ and $\mathrm{H}_{2}$ in several gas mixtures. Tables 1 and 2 consist of properties of some MOFs measured at high and low pressures, respectively. Comparing the results in both tables shows that higher selectivities are somewhat guaranteed at low pressures than at high pressures. The highest recorded selectivity was obtained for UTSA-49 in Table 2, with a selectivity of $95.8 \%$ at 1 bar and $298 \mathrm{~K}$.

Since studies on the sequestration of other carbonaceous substances are rare in the literature, the three processes itemized in "(1), (2), and (3)" can be tried for the different MOFs discussed in line with their capacities to trap $\mathrm{CH}_{4}$, $\mathrm{CHCl}_{3}, \mathrm{CCl}_{4}, \mathrm{CH}_{2} \mathrm{Cl}_{2}$, and their compatibilities with the substances.

Reports have it that polymers of intrinsic microporosity (PIM) are also prospective starting materials for the synthesis of ultrapermeable thin-film composite (TFC) membranes. This is because PIMs are known to provide advantages including high fractional free volume (FFV), good mechanical and film-forming characteristics, and excellent processability which provide for high $\mathrm{CO}_{2}$ selectivity of the material [135]. In lieu of the aforementioned properties, pristine PIMs are usually associated with shortcomings ranging from physical aging to low $\mathrm{CO}_{2} / \mathrm{N}_{2}$ selectivity $(<20)$ which limit their industrial application. The detrimental aging effect of PIMs is somewhat evident in TFC assemblies, especially in situations where a 90\% drop in $\mathrm{CO}_{2}$ permeance was clearly ascribed to the physical aging of the composite material $[136,137]$. In order to offset the aging problem associated with TFCs, a TFC membrane codoped with a polymer of intrinsic microporosity such as the PIM-1 was hybridized with nano-MOFs (i.e., MOF-74-Ni and $\mathrm{NH}_{2}$-UiO-66 nanoparticles) and adopted for postcombustion $\mathrm{CO}_{2}$ capture [138]. The design of the TFC membrane comprised of three layers, i.e., (i) a PIM-1@MOF mixed matrix $\mathrm{CO}_{2}$-selective layer; (ii) an ultrapermeable polydimethylsiloxane (PDMS) gutter layer impregnated 
TABle 1: Properties of MOFs and MOF-based membranes measured at pressures of 8.5-224.99 bar.

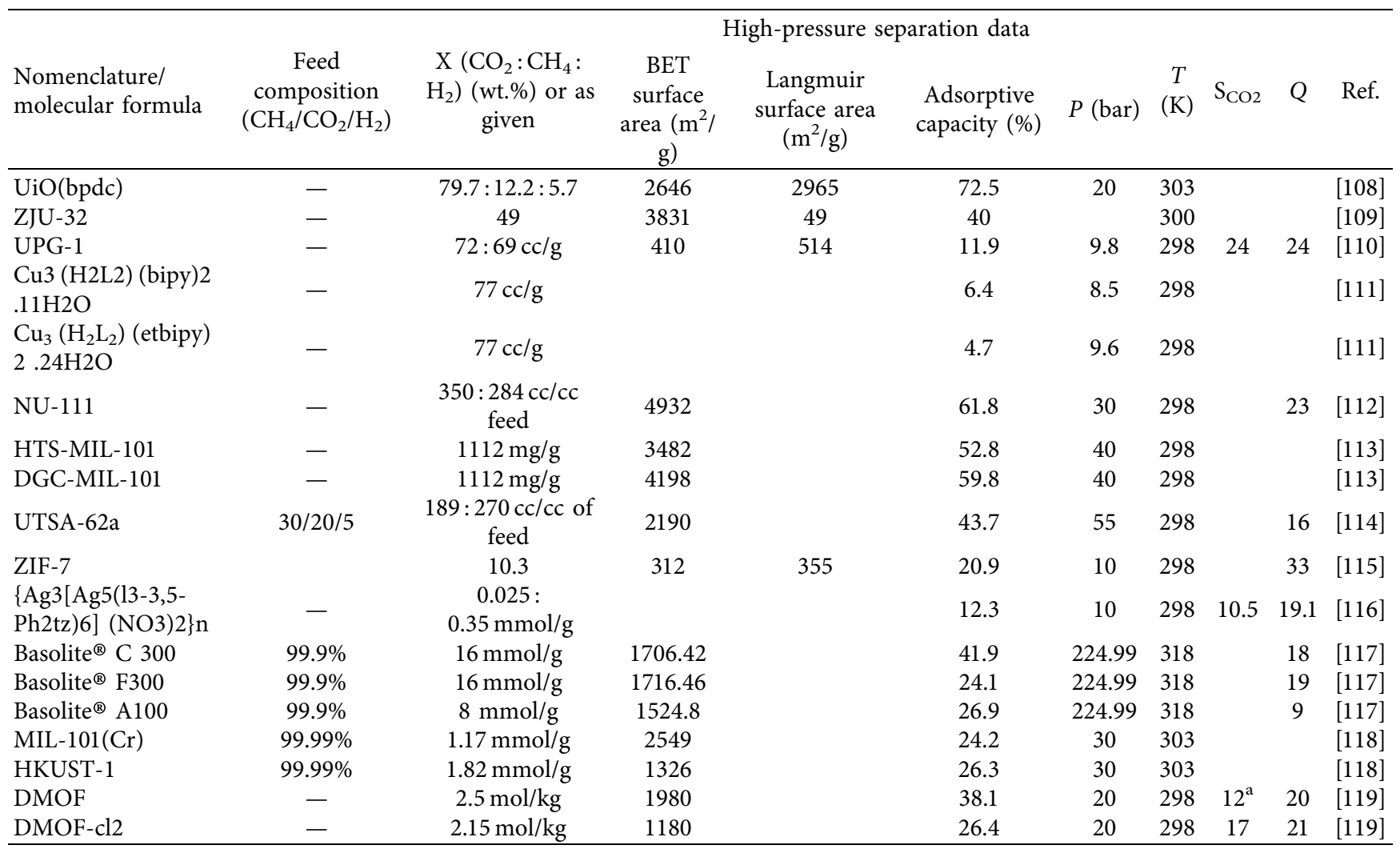

${ }^{*} \mathrm{X}=\mathrm{CO}_{2}$ uptake

with $\mathrm{MOF}$ nanosheets that provides for $\mathrm{CO}_{2}$ permeance in the range of 10,000-11,000 gas permeation unit (GPU), thus allowing for less $\mathrm{CO}_{2}$ transport resistance relative to the pristine PDMS gutter layers; and (iii) a third porous polymeric substrate-layer. Furthermore, by blending the nanosized MOF particles into the PIM-1, the resulting TFC membrane assembly gave high permeation of $\mathrm{CO}_{2}$ in the region of 4660-7460 GPU with $\mathrm{CO}_{2} / \mathrm{N}_{2}$ selectivity ranging from 26 to 33 as compared with that of the pristine PIM-1, which gave $\mathrm{CO}_{2}$ permeance of 4320 GPU with corresponding $\mathrm{CO}_{2} / \mathrm{N}_{2}$ selectivity of 19 . In addition, the PIM1-MOF-based TFC membrane was seen to exhibit enhanced resistance to aging effect, thus maintaining a constant $\mathrm{CO}_{2}$ permeance in the region of 900-1200 GPU with $\mathrm{CO}_{2} / \mathrm{N}_{2}$ selectivity of 26-30 after 8 weeks.

Other works on PIM for $\mathrm{CO}_{2}$ capture include the work of Bhavsar et al. [139] where ultrapermeable PIM thin-film nanocomposite membranes were anchored on microporous polyacrylonitrile (PAN) supports for effective $\mathrm{CO}_{2}$ capture. Borisov et al. [136] also carried out an investigation of gas $\left(\mathrm{CO}_{2} / \mathrm{N}_{2}\right)$ selectivity in thin-film PIM-1 composite membranes where they established the potential of the membrane for adsorbing both gases. However, it was also observed that the selectivity of the membrane for each gas decreased over the aging period of the membrane. Liang et al. [140] also allotted the performance of multilayer PIM composite hollow fibers to their intrinsic microporous multilayer gutters. In addition, the studies conducted by Tiwari et al.
[141] and Swaidan et al. [142] bother on the examination of the aging period, plasticization, and $\mathrm{CO}_{2}$ adsorptive performance of a synthetic thin-film and rigid PIM-1 membranes, respectively.

Three-phase mixed matrix membranes comprising of poly (ether-block-amide (PEBA), polyethylene glycol (PEG), and nanozeolite $\mathrm{X}$ were produced; the effects of the PEG and/or the nanozeolite on $\mathrm{CO}_{2}$ and $\mathrm{CH}_{4}$ permeabilities and $\mathrm{CO}_{2} / \mathrm{CH}_{4}$ selectivity of the membranes were examined. The $\mathrm{CO}_{2}$ permeability and selectivity of the membranes were seen to increase with feed pressure and PEG loading. However, at a pressure of 8 bar, the PEBA membrane doped with $30 \%$ PEG and $10 \%$ nanozeolite $\mathrm{X}$ gave the best performance with $\mathrm{CO}_{2}$ permeability and $\mathrm{CO}_{2} / \mathrm{CH}_{4}$ selectivity 95 Barrer and 45, respectively [143].

Synthetic ionic liquid (3-di-n-butyl-2-methylimidazolium chloride (DnBMCl)) was used in modifying a sample Pebax 1657 surface as a means of strengthening the carbon-carbon bond in the mixed polymer matrix [144]. By the coating method, ZIF- 8 nanoparticles produced from different precursor ratios were doped in the matrix of the ILPebax 1657 system in order to fabricate the mixed matrix membranes (MMMs). Tests such as SEM, DSC, FTIR, 13C NMR, TGA, and gas permeation analysis were used to characterize and evaluate the performance of the MMMs. Based on the results of the gas permeation tests conducted, increased $\mathrm{CO}_{2} / \mathrm{CH}_{4}, \mathrm{CO}_{2} / \mathrm{N}_{2}$, and $\mathrm{CO}_{2} / \mathrm{H}_{2}$ selectivities were observed for the modified $\mathrm{DnBMCl}-\mathrm{MMM}$ relative to the 
TABle 2: Properties of MOFs and MOF-based membranes measured at pressures of 0.91-1.01 bar.

\begin{tabular}{|c|c|c|c|c|c|c|c|c|c|c|}
\hline & & $\mathrm{X}\left(\mathrm{CO}_{2}:\right.$ & Lon & -pressure sep & aration data & & & & & \\
\hline $\begin{array}{l}\text { Nomenclature/ } \\
\text { molecular formula }\end{array}$ & $\begin{array}{c}\text { Feed } \\
\text { condition } \\
\left(\mathrm{CO}_{2}: \mathrm{N}_{2}\right)\end{array}$ & $\begin{array}{c}\left.\mathrm{CH}_{4}: \mathrm{H}_{2}\right) \\
\text { uptake } \\
\text { (wt.\%) }\end{array}$ & $\begin{array}{l}\text { BET surface } \\
\text { area }\left(\mathrm{m}^{2} / \mathrm{g}\right)\end{array}$ & $\begin{array}{l}\text { Langmuir } \\
\text { surface } \\
\text { area }\left(\mathrm{m}^{2} / \mathrm{g}\right)\end{array}$ & $\begin{array}{l}\text { Adsorptive } \\
\text { capacity }\end{array}$ & $P$ (bar) & $T(\mathrm{~K})$ & $\mathrm{S}_{\mathrm{CO} 2}$ & $\begin{array}{c}Q \\
\left(\mathrm{kJmol}^{-1}\right)\end{array}$ & Ref. \\
\hline rht-MOF-pyr & & $112: 17 \mathrm{cc} / \mathrm{g}$ & 2100 & & 12.7 & 1 & 298 & & 28 & {$[120]$} \\
\hline rht-MOF-1 & & $90: 16.4$ & 2100 & & 11 & 1 & 298 & & 29 & {$[120]$} \\
\hline JLU-Liu22 & & $170 \mathrm{cc} / \mathrm{g}$ & 1487 & & 15.6 & 1 & 298 & & 30 & [121] \\
\hline SIFSIX-3-Co & $15: 85$ & $62.6 \mathrm{cc} / \mathrm{g}$ & 223 & & 10 & 1 & 298 & & 47 & [122] \\
\hline $\begin{array}{l}\text { SIFSIX-3-Ni } \\
\left\{\left[\mathrm{H}_{2} \mathrm{~N}\left(\mathrm{CH}_{3}\right)_{2}\right] 4\right.\end{array}$ & - & 64.5 & 368 & & 10.3 & 1 & 298 & & 59 & [122] \\
\hline $\begin{array}{l}{\left[\mathrm{Zn} 9 \mathrm{O}_{2}(\mathrm{BTC}) 6\right.} \\
\left.\left.(\mathrm{H} 2 \mathrm{O})_{3}\right] .3 \mathrm{DMA}\right\} \mathrm{cn}\end{array}$ & - & $99: 63 \mathrm{cc} / \mathrm{g}$ & 844 & 1132 & 10.9 & 0.91 & 298 & & 29 & [123] \\
\hline $\begin{array}{l}\left\{\left[\mathrm{NH}_{2}\left(\mathrm{CH}_{3}\right)_{2}\right.\right. \\
\mathrm{Cd}(\mathrm{BTC})] . \mathrm{DMA}\} n\end{array}$ & - & $32: 23 \mathrm{cc} / \mathrm{g}$ & 406 & 539 & 6.4 & 0.91 & 298 & 30 & 34.7 & [123] \\
\hline Ni-DOBDC & & $2.30 \mathrm{~mol} / \mathrm{kg}$ & 798 & & 18.2 & 1 & 298 & & & [124] \\
\hline Py-Ni-DOBDC & & $1.64 \mathrm{~mol} / \mathrm{kg}$ & 409 & & 12 & 1 & 298 & & 16 & [124] \\
\hline $\mathrm{UiO}(\mathrm{bpdc})$ & - & 8 & 2646 & 2965 & 8 & 1 & 303 & & & [108] \\
\hline ZJU-32 & - & $0.1: 0.01$ & 3831 & & 4.8 & 1 & 300 & & & [109] \\
\hline $\begin{array}{l}\mathrm{Zn}(5-\mathrm{mtz})(2- \\
\text { eim).(guest) [ZTIF- } \\
1]\end{array}$ & & $49: 13.16 \mathrm{cc} / \mathrm{g}$ & 1430 & 1981 & 8.2 & 1 & 295 & 81 & 22.5 & [125] \\
\hline $\begin{array}{l}\mathrm{Zn}(5-\mathrm{mtz})(2- \\
\text { pim).(guest) [ZTIF- } \\
2]\end{array}$ & & $29.3 \mathrm{cc} / \mathrm{g}$ & 1287 & 1461 & 3.8 & 1 & 295 & & 20 & [125] \\
\hline $\begin{array}{l}\text { UTSA-49 } 10: 90 \\
15: 85 \\
20: 80\end{array}$ & & $69 \mathrm{cc} / \mathrm{g}$ & 710.5 & 1046.6 & 13.6 & 1 & 298 & 95.8 & & [126] \\
\hline ZJNU-40 5:95 & & $108 \mathrm{cc} / \mathrm{g}$ & 2209 & & 16.4 & 1.01 & 296 & & 18.4 & [127] \\
\hline UPG-1 & - & 22 & 410 & 514 & 2.1 & 1 & 298 & 24 & 24 & [110] \\
\hline UiO-66(Zr100) & & $2.2 \mathrm{mmol} / \mathrm{g}$ & 1390 & 1644 & 6.2 & 1 & 298 & & 26 & [128] \\
\hline $\begin{array}{l}\mathrm{UiO}-66(\mathrm{Ti} 32) \text { and } \\
\mathrm{UiO}-66(\mathrm{Zr} / \mathrm{Ti})\end{array}$ & & $\begin{array}{l}2.3 \text { and } \\
4 \mathrm{mmol} / \mathrm{g}\end{array}$ & 1418 & 1703 & 6.4 & 1 & 298 & & 28 & [128] \\
\hline UiO-66(Ti44) & - & $2.3 \mathrm{cc} / \mathrm{g}$ & 1749 & 2088 & 7.2 & 1 & 298 & & 34 & [128] \\
\hline JLU-Liu1 & - & $34.7: 0.5 \mathrm{cc} / \mathrm{g}$ & 145 & 221 & 5.9 & 1 & 298 & & 47.7 & [129] \\
\hline UTSA-62a 30/20/5 & & $\begin{array}{l}189: 270 \mathrm{ccl} \\
\mathrm{cc} \text { of feed }\end{array}$ & 2190 & & 8.1 & 1 & 298 & & 16 & [114] \\
\hline Zn-DABCO & $60-100 \mathrm{mg}$ & $1.87 \mathrm{mmol} / \mathrm{g}$ & 1870 & 1902 & 7.2 & 1 & 298 & & 22.4 & {$[87]$} \\
\hline $\mathrm{Ni}-\mathrm{DABCO}$ & $60-100 \mathrm{mg}$ & $\begin{array}{c}2.17: \\
0.51 \mathrm{mmol} / \mathrm{g}\end{array}$ & 2120 & 2219 & 8.1 & 1 & 298 & & 25.8 & [87] \\
\hline Co-DABCO & $60-100 \mathrm{mg}$ & $\begin{array}{c}1.02: \\
0.57 \mathrm{mmol} / \mathrm{g}\end{array}$ & 2022 & 2095 & 4.1 & 1 & 298 & & 29.8 & [87] \\
\hline $\mathrm{Mg} / \mathrm{DOBDC}$ & $40: 60 \mathrm{v} / \mathrm{v}$ & $180 \mathrm{cc} / \mathrm{g}$ & 1415.1 & & 25 & 1 & 298 & & 47 & {$[88]$} \\
\hline $\begin{array}{l}\left\{\mathrm{Ag}_{3}\left[\mathrm{Ag}_{5}(\mathrm{l} 3-3,5-\right.\right. \\
\left.\left.\left.\mathrm{Ph}_{2} \mathrm{tz}\right)_{6}\right]\left(\mathrm{NO}_{3}\right)_{2}\right\} n\end{array}$ & - & $\begin{array}{c}\text { 7-8 } \mathrm{CO}_{2} \\
\text { molecules/ } \\
\text { unit } \\
\text { adsorbent } \\
(0.39 \mathrm{mmol} / \\
\mathrm{g})\end{array}$ & & & 1.6 & 1 & 298 & 10.5 & 19.1 & [116] \\
\hline $\begin{array}{l}\left\{\mathrm{Ag}_{3}\left[\mathrm{Ag}_{5}(\mathrm{l} 3-\right.\right. \\
\left.\left.\left.3,5 \mathrm{tBu}_{2} \mathrm{tz}\right)_{6}\right]\left(\mathrm{BF}_{4}\right)_{2}\right\} n\end{array}$ & - & $0.37 \mathrm{mmol} / \mathrm{g}$ & & & 1.6 & 1 & 298 & 14 & 15 & [116] \\
\hline Basolite $^{\circledR}$ C 300 & & $2 \mathrm{mmol} / \mathrm{g}$ & 1706.42 & & 9.4 & 0.95 & 318 & & 18 & [117] \\
\hline Basolite ${ }^{\circledR}$ F300 & & $0.5 \mathrm{mmol} / \mathrm{g}$ & 1716.46 & & 2,4 & 0.95 & 318 & & 19 & [117] \\
\hline CPM-5 & & & 2187 & & 8.8 & 1 & 298 & 16.1 & 36.1 & [130] \\
\hline $\begin{array}{l}\text { ZIF-68 15:10:75 } \\
\left(\mathrm{CO}_{2}: \mathrm{SO}_{2}: \mathrm{N}_{2}\right)\end{array}$ & & $1.6 \mathrm{~mol} / \mathrm{kg}$ & 1220 & & 41.3 & 0.9 & 298 & 30 & 33.3 & [131] \\
\hline $\mathrm{Zn}_{4}($ bpta $) 2-1$ - & & $41.95 \mathrm{~cm}^{3} / \mathrm{g}$ & & 51 & 8.2 & 1.2 & 298 & 23 & 34.82 & [132] \\
\hline $\begin{array}{l}\mathrm{Cu}_{2} \mathrm{~L}(\mathrm{DMA})_{4} \\
\mathrm{UHP} \text {-grade }\end{array}$ & $\begin{array}{l}\text { UHP- } \\
\text { grade } \\
99.99 \%\end{array}$ & $160 \mathrm{~cm}^{3} / \mathrm{g}$ & 1433 & & 22.2 & 1 & 296 & 41.6 & 35 & [133] \\
\hline bio-MOF-11 & $\begin{array}{c}10: 90 \\
\left(\mathrm{CO}_{2}: \mathrm{N}_{2}\right)\end{array}$ & $147 \mathrm{~cm}^{3} / \mathrm{g}$ & 1148 & & 22.2 & 1 & 273 & 123 & 33.1 & [134] \\
\hline bio-MOF-14 & $\begin{array}{c}10: 90 \\
\left(\mathrm{CO}_{2}: \mathrm{N}_{2}\right)\end{array}$ & $44.8 \mathrm{~cm}^{3} / \mathrm{g}$ & & 17 & 8 & 1 & 273 & $\begin{array}{c}\text { Extremely } \\
\text { high }\end{array}$ & - & [134] \\
\hline
\end{tabular}


MM and pristine Pebax 1657 membranes. Also, they asserted that the inferior $\mathrm{CO}_{2}$ separation ability exhibited by the MMMs in the mixed-gas condition compared to the situation where pure gas was adopted for the test was influenced by the effect of plasticization in the MMMs. In addition, the modified DnBM-Pebax 1657-ZIF-8 MMMs exhibited superior $\mathrm{CO}_{2} / \mathrm{CH}_{4}$ and $\mathrm{CO}_{2} / \mathrm{N}_{2}$ selectivities at feed pressures of 2 and 4 bar, respectively. The study by Sutrisna et al. [145] involves the comparison of the operational stability of Pebax modified with ZIF-8 for gas separation with flat sheet and composite hollow Pebax fibre membranes. Also, the modified ZIF- 8 was found to be stable alongside the pristine ZIF- 8 due to the hydrogen bonds and the polyamide chains present in both samples, and these were reported to have improved the stiffness of the linear glassy polymer chains, thus ensuring good operational stability of the membranes at high pressure for the flat sheet and hollow fibre membranes. In addition, the outstanding long-term stability of the hollow fibre membrane suggests that the ZIF-8/Pebax coating improved the aging resistance of the poly[1-(trimethylsilyl)-1-propyne] (PTMSP) gutter layer. The poly (ether-block-amide) (Pebax) mixed matrix membranes (MMMs) were prepared using size-tunable nanoparticles of ZIF-8 nanofillers $(40,60,90$, and $110 \mathrm{~nm}$, i.e., ZIF-8-40, ZIF-8-60, ZIF-8-90, and ZIF-8-110) synthesized from $98 \%$ zinc acetate dehydrate $\left(\mathrm{Zn}(\mathrm{COO})_{2} \cdot 2 \mathrm{H}_{2} \mathrm{O}\right)$ and 98\% 2-methylimidazole ( $\left.\mathrm{Hmim}, \mathrm{C}_{4} \mathrm{H}_{6} \mathrm{~N}_{2}\right)$ [146]. The ZIF-8 nanofillers were produced in microemulsion by controlling the ratio of $\mathrm{Zn}^{2+}$ to $\operatorname{Hmim}(1: 16,1: 8,1: 5$, and $1: 2$ ). They were then uniformly distributed in the Pebax matrix without visible agglomerations/defects at loadings of 0-20 wt.\% as confirmed by FESEM. Based on the results, the ZIF-8 significantly improved the $\mathrm{CO}_{2}$ permeability and $\mathrm{CO}_{2} /$ $\mathrm{N}_{2}$ selectivity of the MMM. The enhanced permeability of the MMM was attributed to the induced free/pore volume of the polymer caused by the integration of larger sized ZIF-8. The resulting increase in the selectivity of the MMM was allotted to the high surface area of the ZIF- 8 nanofillers, which provided more active sites for $\mathrm{CO}_{2}$ capture with improved resistance to mass transfer for $\mathrm{N}_{2}$. For $5 \mathrm{wt} \%$ loading of the ZIF8-90, the MMM had the best $\mathrm{CO}_{2}$ separation performance with a permeability of 99.7 Barrer and $\mathrm{CO}_{2} / \mathrm{N}_{2}$ selectivity of 59.6 , which both gave a marginal increase of about $25 \%$ when compared to the pristine Pebax membrane.

In the work of Beni and Shahrak [147], pristine zeolites (ZIF-8 and ZIF-90) were synthesized and compared with samples of both zeolites functionalized with $\mathrm{Li}, \mathrm{K}$, and $\mathrm{Na}$ cations. Based on the $\mathrm{CO}_{2}$ adsorption tests conducted, the Li-functionalized zeolites gave the highest $\mathrm{CO}_{2}$ uptake for both zeolites and these they allotted to have been enhanced by the interactions (i.e., electrostatic and dispersion interactions) that occurred between the adsorbate and adsorbent molecules which gave rise to higher binding energies. Simulation results also revealed that, at 1 bar and $298 \mathrm{~K}$, the $\mathrm{CO}_{2}$ uptakes for the Li-functionalized ZIF- 8 and ZIF-90 increased by 7 and 9 times over their pristine counterparts, thus giving values of 6 and $9 \mathrm{mmol} / \mathrm{g} \mathrm{CO}_{2}$ uptake, respectively. The Li-functionalized-ZIFs exemplified chemisorption as informed by their calculated heats of adsorption which also provides vital information for efficient regeneration of the adsorbents in pragmatic situations.

1.2.4. Microbial and Algal Seed Coats: Contextualizing Regenerative Agriculture. Along farmlands on the East Coast of Australia, efforts are being put in place by farmers to test modern approaches of combatting climate change. One of such measures involves planting seeds that are coated with fungi and bacteria with the intent of capturing $\mathrm{CO}_{2}$ from air [148]; according to reports, the plan is to sink billions of tons of carbon into farmlands. There are also speculations that the coated seeds exhibit a higher carbon capture potential than a carbon capture plant. A start-up firm, known as the Soil Carbon Company, is working on a modern technology whose origin is traceable to the University of Sydney where the annual projections on the carbon sequestration potential of the technology are 8.5 gigatons carbon or one-fourth of the global annual $\mathrm{CO}_{2}$ emissions in a year. There are also projections that this technology can store trapped carbon for a longer time than some regenerative agricultural carbon capture technologies. Injecting microbes into crops on a farmland/plantation enhances the carbon storage capacity of plants since all plants make use of atmospheric carbon dioxide in their normal carbon cycles during photosynthesis; the absorbed carbon traverses the plant roots before ending up in the soil. However, some of the trapped carbon is fairly lost in the surrounding air. This then informed the idea of coating plant seeds with fungi and bacteria that can convert the trapped carbon into a form that can be stored much longer in soils over a long period of time, say hundreds of years. This technology is promising but is yet to gain full support for commercialization. Based on some findings, the process will enrich the soil and reduce the need for high amount of fertilizers.

Another technology that bothers on the use of microbes is microbial electrolytic carbon capture (MECC) which employs microbial electrolytic cells during wastewater treatment. The process/treatment brings about net negative carbon emissions from wastewater by simply converting the inherent $\mathrm{CO}_{2}$ in water to calcite/limestone (CaCO3) [149] with the release of high amount of hydrogen gas that can be harnessed for other profitable ventures. $\mathrm{CO}_{2}$ from anthropogenic sources contributes significantly to the regional dynamics of climate change as a result of the greenhouse gases released into the atmosphere from such processes. Most $\mathrm{CO}_{2}$ mitigation practices are fossil fuel-based, which give off other compounds such as SOx and NOx during combustion. No doubt, a nation's economic growth relies on its capacity for energy generation and how energy efficient it is, i.e., in terms of energy production for transportation and production of industry goods and services. $\mathrm{CO}_{2}$ from wastewater processing contributes a small percentage (i.e., about 15\%) to the global greenhouse gas emissions [150]; presently, about $3 \%$ of the total electricity generated within the US is channeled to wastewater treatment facilities which have a capacity of 12 trillion gallons of wastewater per year. 
MECC contributes significantly to sustainable energy practice, owing to the fact that it takes advantage of the properties of the organic constituents of wastewater for eliminating carbon-based compounds $/ \mathrm{CO}_{2}$ in order to produce a precipitate (calcite) alongside $\mathrm{H}_{2}$ [151]. Operators of wastewater treatment facilities are held accountable for their greenhouse gas emissions during wastewater treatment by the Greenhouse Gas Protocol Initiative. For instance, the process is energy-intensive as it requires energy for the aeration process, which in turn releases volatile compounds from wastewater, during the agitation and transportation of polluted and recycled fluids within the entire process. The electricity used in wastewater treatment gives carbon dioxide, methane, and NOx gases; the aerobic treatment step gives off $\mathrm{N}_{2} \mathrm{O}$ and $\mathrm{CO}_{2}$, whereas the sedimentation and activated sludge steps produce $\mathrm{CO}_{2}$ and $\mathrm{CH}_{4}$.

\subsubsection{Adsorption: Packed Beds (Alumina/Activated Carbon/} Zeolite), Graphene, and Monolith-Molecular Sieves (CarbonCoated Substrate and Carbon-Carbon Fibre Monolith). Solid adsorbents such as zeolite/activated carbon can be employed in trapping $\mathrm{CO}_{2}$ from gaseous mixtures at high pressures/temperatures. During pressure swing adsorption (PSA), gas flows through one or more packed beds of adsorbent at high pressure until the concentration of the gas progressively attains equilibrium (Figure 6). Thereafter, the bed is regenerated by reversing the pressure, whereas, in temperature swing adsorption (TSA), sorbent regeneration or gas desorption occurs by an increase in temperature. The adsorption of $\mathrm{CO}_{2}$ onto solid adsorbents is not considered economically viable for the recovery of large volumes of $\mathrm{CO}_{2}$ from flue gas, due to the low capacity of these adsorbents as well as their $\mathrm{CO}_{2}$ selectivities $[152,153]$. However, hybrid systems or a combination of several carbon capture technologies may become necessary in order to make these processes economically viable.

Zeolites are aluminosilicates with well-defined micro/ ultrasmall porous structures, thermal stability, recyclability, and chemical reactivity [154]. They are rated as high-performing adsorbents [155-158]. Some zeolite networks have been tested for their abilities to trap $\mathrm{CO}_{2}$ under different humid conditions, and the adsorption process was simulated using the Monte Carlo simulation [159]. Although under wet conditions, a rise in $\mathrm{CO}_{2}$ uptake of pure zeolites has not been confirmed experimentally, however, there are speculations that the $\mathrm{CO}_{2}$ uptake of some zeolite structures is expected to rise under moist conditions [12]. For porous adsorbents such as zeolites, $\mathrm{CO}_{2}$ storage is predominately seen to be caused by adsorbate-adsorbate interactions [159], which is in contrast to the case of selective $\mathrm{CO}_{2}$ sequestration that is largely influenced by adsorbent-adsorbate interactions or their chemical affinity for $\mathrm{CO}_{2}$ at low pressures [160].

No doubt, zeolites are potential adsorbents for $\mathrm{CO}_{2}$ capture; however, their adsorption efficiencies are usually influenced by their chemical constituents/composition, charge density, and pore size. Highly crystalline zeolites with three-dimensional pores and high surface areas can be obtained by controlling the $\mathrm{Si} / \mathrm{Al}$ ratio in the zeolite matrix.
The notable influence of the presence of alkali/alkaline earth cations in zeolite matrices is another subject yet to be fully explored; thus, optimizing the composition of a sample zeolite may somewhat alter its $\mathrm{CO}_{2}$ adsorption capacity, which is also justified by the work of Balashankar and Rajendran [161], who optimized a zeolite screening process for postcombustion trapping of $\mathrm{CO}_{2}$ under vacuum swing adsorption in order to determine the optimal conditions for high efficiency. In lieu of the myriad of approaches adopted for increasing the $\mathrm{CO}_{2}$ adsorptive capacities of zeolites, they still present some shortcomings which include their relatively low $\mathrm{CO}_{2} / \mathrm{N}_{2}$ selectivity when compared with their $\mathrm{CO}_{2}$ adsorption potentials/high hydrophilicity, especially in feed mixtures containing both gases. Nonetheless, the $\mathrm{CO}_{2} \mathrm{ab}-$ sorptive capacities of zeolites may likely decrease especially in situations where the $\mathrm{CO}_{2} / \mathrm{N}_{2}$ mixtures are entrained with moisture. Also, upon adsorption, zeolite regeneration is only achievable at temperatures $\left(>300{ }^{\circ} \mathrm{C}\right)$ [162].

The $\mathrm{CO}_{2}$ capture potential of zeolites has been widely discussed owing to their molecular sieving abilities and strong dipole-quadrupole/electrostatic interactions that exist between $\mathrm{CO}_{2}$ and the alkali/alkali-earth-metal cations ( $\mathrm{Li}, \mathrm{Na}$, and $\mathrm{Al}$ ) in the zeolite matrices [163]. These cations influence the heat of adsorption of $\mathrm{CO}_{2}$, such that it increases with a corresponding increase in the monovalent charge density of the inherent negative charges in the material $[164,165]$. Zeolites $13 \mathrm{X}$ and 5A have been reported to give high $\mathrm{CO}_{2}$ retention/performances in the range of $3-25 \mathrm{wt} . \%$ at room temperature and $\mathrm{CO}_{2}$ pressure of $100 \%$ $[3,166-168]$; they also recorded a $\mathrm{CO}_{2}$ capture of $2-12 \mathrm{wt} . \%$ at room temperature and a $\mathrm{CO}_{2}$ partial pressure of $15 \%$ [169-171]. Cavenati et al. [172] demonstrated the ability of zeolite $13 \mathrm{X}$ as a suitable adsorbent for $\mathrm{CO}_{2}$; they recorded a $\mathrm{CO}_{2}$ capture of $28.7 \mathrm{wt} . \%$ and $\mathrm{CO}_{2} / \mathrm{N}_{2}$ separation capacity of 3.65 at $298 \mathrm{~K}$ and 10 bar. The work of Jadhav et al. [173] bothers on the modification of zeolite $13 \mathrm{X}$ using monoethanolamine (MEA) impregnation in order to improve its $\mathrm{CO}_{2}$ trapping capacity. The $\mathrm{CO}_{2}$ adsorption capacity of the modified zeolite $13 \mathrm{X}$ was seen to be better than that of the pristine zeolite by a factor of about 1.6 at $303 \mathrm{~K}$, while at a temperature of $393 \mathrm{~K}$, the efficiency was seen to improve by a factor of 3.5. However, in lieu of the reduction in pore volume and surface area that ensued from the MEA impregnation, they asserted that the improved capacity of the modified zeolite $13 \mathrm{X}$ was due to the chemical interactions between $\mathrm{CO}_{2}$ and the infused amine groups. Zeolites 13X and $5 \mathrm{~A}$ impregnated with $\mathrm{LiOH}$ (LEZ-13X and LEZ-5A) were used to trap $\mathrm{CO}_{2}$ under ambient conditions. Based on the BET analysis, the surface areas of the $\mathrm{LiOH}$-doped sorbents were much smaller than those of the undoped zeolite. Also, the $\mathrm{LiOH}$-doped zeolites gave higher $\mathrm{CO}_{2}$ adsorption relative to the bare zeolite when in contact with air/oxygen. An optimization of the optimum moisture content for maximum $\mathrm{CO}_{2}$ removal was carried out by correlating the measured relative humidity $(\mathrm{RH})$ with $\mathrm{CO}_{2}$ uptake [174].

Some recent advances in the use of graphene have also shown its potential as a suitable adsorbent for $\mathrm{GHGs} / \mathrm{CO}_{2}$. Graphene is a $2 \mathrm{D}$ super carbon-based allotrope with $\mathrm{Sp}^{2}$ 


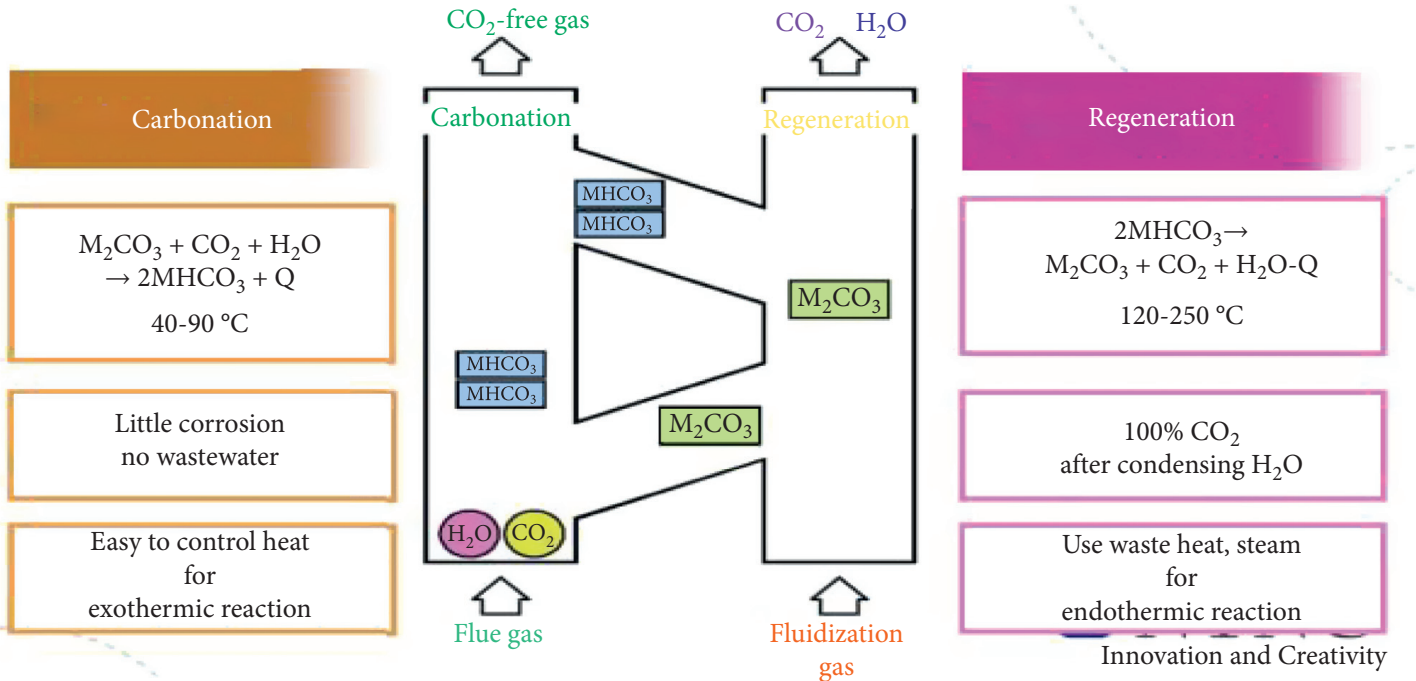

Figure 6: Dry sorbent $\mathrm{CO}_{2}$ capture with fluidized beds and adsorbent regeneration (adopted from Bolland [44]).

hybridized atomic layers [175]. Graphene and its derivatives are potential materials for effective $\mathrm{CO}_{2}$ capture [176-181]. According to Kemp et al. [182], this happens by reason of the grafting of compatible functional groups onto graphene layers, thus giving rise to highly stable $\mathrm{N}$-doped graphene composites with surface areas in the region of $1336 \mathrm{~m}^{2} / \mathrm{g}$ and reversible $\mathrm{CO}_{2}$ capacity of $2.7 \mathrm{mmol} / \mathrm{g}$ at $298 \mathrm{~K}$ and $1 \mathrm{~atm}$ for repeated adsorption cycles. Oh et al. [183] studied the performance of borane-modified graphene; they reported a $\mathrm{CO}_{2}$ uptake of $1.82 \mathrm{mmol} / \mathrm{g}$ at $1 \mathrm{~atm}$ and $298 \mathrm{~K}$. New hybrid systems such as mesoporous graphene oxide (mGO)- $\mathrm{ZnO}$ nanocomposite [184], mesoporous $\mathrm{TiO}_{2}$-graphene oxide nanocomposites [185], Mg-Al layered double hydroxide (LDH) graphene oxide [186], MOF-5-aminated graphite oxide (aGO) [187], UiO-66-graphene oxide composites [188], as well as MIL-53(Al)-graphene nanoplates (GNP) [189] have shown improved $\mathrm{CO}_{2}$ adsorptive properties over their nonhybrid counterparts. Table 3 gives a summary of the advances made in different categories of carbon sequestration technologies.

The certification of materials as good adsorbents for $\mathrm{CO}_{2}$ separation from flue gas depends on the following criteria:

(i) Adsorptive capacity: this gives information on the quantity of $\mathrm{CO}_{2}$ that can be trapped on the surface of the solid adsorbent. It is defined as the gravimetric or volumetric uptake of $\mathrm{CO}_{2}$ per unit mass of adsorbent (i.e., grams or volume of $\mathrm{CO}_{2} /$ grams of adsorbent). This dictates the amount of sorbent as well as the size of the adsorbent/packed bed required for a particular operation. The adsorptive capacity of a solid adsorbent determines the energy required during the adsorbent regeneration step.

(ii) Selectivity: this is defined as the $\mathrm{CO}_{2}$ uptake ratio with respect to another gas (i.e., $\mathrm{N}_{2}$ during postcombustion $\mathrm{CO}_{2}$ capture or $\mathrm{CH}_{4}$ in $\mathrm{CO}_{2}$ sequestration from natural gas). The adsorbent selectivity for carbon-based compounds has a resultant effect on the purity of the adsorbed gas [190]. The simplest approach for estimating the selectivity of a solid adsorbent is to evaluate its adsorption profile based on the single-component adsorption isotherms of $\mathrm{CO}_{2}$ and $\mathrm{N}_{2}$.

(iii) Enthalpy of adsorption: this is the amount of energy required to regenerate the solid sorbent, which in turn impacts the cost of the regeneration process. It also measures the affinity of the material for $\mathrm{CO}_{2} /$ target-substance in relation to the strength of the adsorbate-adsorbent interactions.

(iv) Chemical, physical, and thermal stabilities: excellent solid adsorbents must be able to demonstrate high stability when in contact with the contaminated streams, especially during the adsorptionregeneration cycle [191].

(v) Hydrostability: essentially, hydrosorbent stability is a necessary requirement for the sustainable performance of solid adsorbents in contact with water vapour. Furthermore, the thermal capacity and conductivity of the adsorbent are also essential properties for solid adsorbents during mass transfer operations.

(vi) Adsorption-desorption kinetics: the time taken for adsorption and adsorbent regeneration greatly relies on the profile of the adsorbate adsorptiondesorption kinetics, which is determined by breakthrough curves. Adsorbents that adsorb and give off adsorbates with ease upon regeneration are more often preferred, owing to the fact that these can be achieved within shorter cycle times for small quantities of adsorbents, which in turn influences the overall cost of trapping the adsorbate.

(vii) Cost of adsorbent: since several adsorbents that exhibit excellent sorption attributes are readily available at low costs, they are rather deemed the most ideal candidates for $\mathrm{CO}_{2}$ capture. In lieu of the advantages gained from the cheap nature of these 
TABLE 3: Summary of advances made in the categories of carbon sequestration technologies.

\begin{tabular}{|c|c|c|c|c|}
\hline $\begin{array}{l}\text { S. } \\
\text { no. }\end{array}$ & $\begin{array}{c}\text { Categories of carbon sequestration } \\
\text { technologies }\end{array}$ & Process type/solvent & $\begin{array}{c}\text { Trapped carbonaceous } \\
\text { gas }\end{array}$ & Refs. \\
\hline \multirow{10}{*}{1} & \multirow{10}{*}{ Physiochemical absorption } & Physical absorption & & \\
\hline & & Selexol: ethers of polyethylene glycol & $\mathrm{CO}_{2}$ & {$[36]$} \\
\hline & & Rectisol: $\left(\mathrm{CH}_{3} \mathrm{OH}\right)$ & $\mathrm{CO}_{2}$ & {$[44]$} \\
\hline & & Fluorinated solvents: $\left(\mathrm{C}_{4} \mathrm{H}_{6} \mathrm{O}_{3}\right)$ & $\mathrm{CH}_{4}$ & {$[53]$} \\
\hline & & Purisol ionic liquids & $\mathrm{CO}_{2 /} \mathrm{CH}_{4}$ & {$[27,53]$} \\
\hline & & Chemical absorption & & \\
\hline & & Monoethanolamine (MEA) & $\mathrm{CO}_{2}$ & {$[55]$} \\
\hline & & Diethanolamine (DEA) & $\mathrm{CO}_{2}$ & [27] \\
\hline & & Methyl diethanolamine (MDEA) & $\mathrm{CO}_{2}$ & {$[56,57]$} \\
\hline & & $\mathrm{Ca}(\mathrm{OH})_{2}+\mathrm{DEA}$ & $\mathrm{CO}_{2}$ & {$[27]$} \\
\hline 2 & Cryogenic separation & Air separation system & $\mathrm{CO}_{2}$ & {$[60,61]$} \\
\hline \multirow{6}{*}{3} & \multirow{6}{*}{ Membrane separation } & Adsorption & & \\
\hline & & $\begin{array}{c}\text { MOP: (BOP-1) functionalized with } \mathrm{Cl} \text { and } \mathrm{NH}_{2} \\
\text { moieties }\end{array}$ & $\mathrm{CO}_{2} / \mathrm{CH}_{4}$ & {$[66,67]$} \\
\hline & & $\begin{array}{l}\text { MOFs: } \\
\text { (i) With open metal sites }\end{array}$ & $\mathrm{CO}_{2}$ & {$[70,71,81,82]$} \\
\hline & & $\begin{array}{l}\text { (ii) With presynthetic modification of organic } \\
\text { ligands }\end{array}$ & $\mathrm{CO}_{2}$ & {$[91-93]$} \\
\hline & & & $\mathrm{CO}_{2}$ & {$[99,102,107]$} \\
\hline & & $\begin{array}{l}\text { (iii) Postsynthetic functionalization of MOF- } \\
\text { metal matrices }\end{array}$ & $\mathrm{CO}_{2}$ and $\mathrm{CH}_{4}$ & {$[107]$} \\
\hline 4 & Microbial and algal seed coats & Regenerative agriculture (MECC) & $\mathrm{CO}_{2}$ and $\mathrm{CH} 4$ & [151] \\
\hline \multirow{10}{*}{5} & \multirow{10}{*}{ Adsorption } & $\begin{array}{l}\text { Zeolite/activated carbon } \\
\text { Graphene }\end{array}$ & $\mathrm{CO}_{2}$ & {$[44,152,153]$} \\
\hline & & (i) Pristine graphene & $\mathrm{CO}_{2} / \mathrm{GHGs}$ & {$[181]$} \\
\hline & & (ii) $\mathrm{N}$-doped & $\mathrm{CO}_{2}$ & [182] \\
\hline & & (iii) Borane-modified graphene & $\mathrm{CO}_{2}$ & [183] \\
\hline & & $\begin{array}{l}\text { (iv) Mesoporous graphene oxide (mGO)- } \mathrm{ZnO} \\
\text { nanocomposite }\end{array}$ & $\mathrm{CO}_{2}$ & {$[184]$} \\
\hline & & (v) Mesoporous $\mathrm{TiO}_{2}$-graphene oxide & $\mathrm{CO}_{2}$ & {$[185]$} \\
\hline & & $\begin{array}{l}\text { (vi) Mg-Al layered double hydroxide (LDH) } \\
\text { graphene oxide }\end{array}$ & $\mathrm{CO}_{2}$ & {$[186]$} \\
\hline & & (vii) MOF-5-aminated graphite oxide (aGO) & $\mathrm{CO}_{2}$ & [187] \\
\hline & & (viii) UiO-66-graphene oxide composites & $\mathrm{CO}_{2}$ & [188] \\
\hline & & (ix) MIL-53(Al)-graphene nanoplates & $\mathrm{CO}_{2}$ & [189] \\
\hline
\end{tabular}

materials, the environmental impact of their synthetic routes is a major hurdle that needs to be overcome. As previously mentioned, some solid adsorbents that have been adopted for the trapping of carbonaceous substances $/ \mathrm{CO}_{2}$ include activated carbon (AC), single/multiwalled carbon nanotubes (CNTs), and graphenes. ACs are inexpensive, porous-amorphous structures, which possess high specific surface areas that serve as gas traps for greenhouse gas (GHG)/CO $\mathrm{CO}_{2}$-uptake [192-194]. Unlike zeolites, one of the basic ills associated with the use of $\mathrm{ACs}$ for $\mathrm{CO}_{2}$ adsorption is that there are no active sites for the gas to bond with the adsorbate as orchestrated by the presence of cations in zeolite. Weak interactions result in low enthalpies of adsorption and sorbent regeneration. ACs give very low $\mathrm{CO}_{2}$ uptake at reduced pressures due to the absence of electric fields on the surfaces of ACs. Kacem et al. [195] carried out a study to test the capacity of ACs and zeolite for $\mathrm{CO}_{2}$ separation from
$\mathrm{N}_{2}$ and $\mathrm{CH}_{4}$ based on their regeneration potential, reusability, and adsorptivity. They observed that the $\mathrm{CO}_{2}$ uptake for ACs was far higher than that of zeolites at pressures above 4 bar. The amount of $\mathrm{CO}_{2}$ recovered at the $\mathrm{AC}$ regeneration stage was purer compared to that recovered from the zeolite samples. In addition, the ACs were found to be more stable in the presence of water vapor, thus resisting any framework collapse [196].

To improve the performance of ACs for $\mathrm{CO}_{2}$ adsorption, amines have been found to be very effective [197-200]. Maria et al. [201] modified the surface of a microporous AC of $80 \%$ active surface via the simultaneous grafting of amine and an amide onto its surface. The work of Gibson et al. [202] bothers on the impregnation of polyamine within the pores of carbon, where the $\mathrm{CO}_{2}$ adsorption was seen to be 12 times that of the undoped carbon. $\mathrm{CO}_{2}$-uptake by $\mathrm{AC}$ has been enhanced by direct impregnation with chitosan and triethylenetetramine onto AC surface, where about 60 and 
$90 \%$ increment in $\mathrm{CO}_{2}$ uptake were recorded at $298 \mathrm{~K}$ and 40 bar. The performance of $\mathrm{NH}_{3}$-modified ACs have been investigated at $1 \mathrm{~atm}$ and within a temperature range of 303 to $333 \mathrm{~K}$ [203]; reports from the investigation showed that the calculated enthalpies of $\mathrm{CO}_{2}$ adsorption for the modified $\mathrm{AC}$ and the piristine $\mathrm{AC}$ are $70.5 \mathrm{kJmol}^{-1}$ and $25.5 \mathrm{kJmol}^{-1}$, respectively, thus indicating that the adsorption process is largely due to chemisorption. At $303 \mathrm{~K}$ and 1 bar, the recorded selectivity and adsorption capacity of the $\mathrm{NH}_{3}-$ modified AC gave corresponding $\mathrm{CO}_{2}$ uptake of $3.22 \mathrm{mmol} /$ $\mathrm{g}$ for the $\mathrm{NH}_{3}$-modified $\mathrm{AC}$ and $2.9 \mathrm{mmol} / \mathrm{g}$ for the unmodified AC [203]. CNTs are very friendly with amine solvents, such that when combined, they are very efficient in the trapping of $\mathrm{CO}_{2}$ [204-208]. Liu et al. [204] synthesized industry-grade CNTs that were functionalized with tetraethylenepentamine (TEPA). The effect of the amine loading on $\mathrm{CO}_{2}$ uptake, enthalpy of adsorption, and adsorbent regeneration was investigated. The TEPA-impregnated CNTs gave a $\mathrm{CO}_{2}$ adsorption rate of $3.09 \mathrm{mmol} / \mathrm{g}$ adsorbent at $343 \mathrm{~K}$. A similar investigation was conducted using 3aminopropyl triethoxy silane (APTES) [209], polyethylenimine (PEI) [206], and di-/tri-ethanolamines [210].

\section{Future Considerations for Carbon Capture Systems}

No doubt, in the near future, greenhouse gas emissions will continue to constitute a global menace to the earth's climate, her populace, and the ecosystem. However, over decades, the literature reveals that concerted efforts were channeled towards abating/controlling $\mathrm{CO}_{2}$ emissions owing to the large volume of $\mathrm{CO}_{2}$ released from fossil fuels. On a unit basis, the amount of other gaseous constituents can be somewhat significant, hence the need to look into trying out some of the methods developed for $\mathrm{CO}_{2}$ capture for their likelihood of being compatible with other greenhouse gases. This then suggests that new methods or modified versions of some existing methods may become necessary in order to achieve this expectation. In addition, there is a need to have a clear understanding of the chemical structure of these gaseous constituents $\left(\mathrm{HCl}_{3}, \mathrm{CCl}_{4}, \mathrm{H}_{2} \mathrm{Cl}_{2}, \mathrm{CH}_{4}\right.$, etc. $)$ and how porous materials can be engineered to ensure their entrapment. The framework of some choice MOFs can be tuned to make them have high selectivity with respect to a target component relative to other gases. For instance, if $\mathrm{CH}_{4}$ is the target gas to be trapped, the matrix of a choice MOF has to be tuned to ensure its selectivity for $\mathrm{CH}_{4}$; the same goes for membranes where high functionalities can be achieved via doping the membranes with nanoparticles or activating them with ionic liquids. This hybrid approach helps to combat the ills associated with using one type of approach per operation because a hybrid system offers the combined abilities of different blends to trap these gaseous constituents. Some of the challenges associated with $\mathrm{CO}_{2}$ capture during postcombustion capture have also been pointed out to include low $\mathrm{CO}_{2}$ partial pressure, high flue gas temperature, and high $\mathrm{CO}_{2}$ concentration in the gas. Also, as already discussed, aqueous amines are suitable for acid gas absorption, but their shortcomings (high costs of solvent regeneration, low $\mathrm{CO}_{2} / \mathrm{H}_{2} \mathrm{~S}$ selectivity, corrosivity, and solvent volatility), these have spiked up a revolution in technological advances, where ionic liquids can be used alongside membranes or MOFs for improved adsorption of not just $\mathrm{CO}_{2}$ but other greenhouse gases.

\section{Conclusion}

Carbon capture systems have proven to be very helpful in reducing the global carbon footprint of the earth. Based on the recent advances recorded in the use of membranes of high thermal, hydrological, and chemical stability, as well as ionic liquids, MOFs, and other solid adsorbents, it is clear that no one adsorbent is an all-time solution to all the greenhouse gas emissions. It then suffices to say that the best solution still lies in creating optimized hybrid capture systems comprising of one or more combinations of MOFs with methyl functionalized ligands [119] + inorganic/ionic liquids; bionanocomposite membranes comprising of $\mathrm{rGO}+\mathrm{DEA}$ or $\mathrm{K}_{2} \mathrm{CO}_{3} /$ $\mathrm{Ca}(\mathrm{OH})_{2}+\mathrm{DEA}$; and zeolite + ionic liquids, etc., for efficient trapping of greenhouse gases.

Despite the potential of each material as a stand-alone technology, the recommendation of the novel hybrid solvents often drifts towards lower energy costs, low solvent loss, low fouling tendencies, and regeneration requirements compared to those associated with conventional amine solvents and this is due to the inherent phase changes that are usually associated with ionic liquids/nonaqueous solvents and enzyme-activation systems which are all promising technologies. For mixtures of low carbon dioxide contents, chemical solvents are usually preferred to physical solvents because physical solvents give better performances at high $\mathrm{CO}_{2}$ partial pressures.

Also, since the presence of fluorine and chlorine functional groups in polymer-/MOF-based membranes help in the adsorption of $\mathrm{CO}_{2}$ [121], the functional groups of the adsorbents can also be tweaked in favour of their adsorptive capacities for $\mathrm{CH}_{4}$ and other carbonaceous gases when polymers/MOFs such as polyhedral metal-organic (PMO) frameworks are being fabricated using supermolecular building blocks functionalized with halogenated solvents of chlorine and fluorine in order to boost their abilities to trap $\mathrm{CO}_{2}$ and some light hydrocarbons including $\mathrm{CH}_{4}$ and $\mathrm{C}_{3} \mathrm{H}_{8}$. Since a large majority of these systems have been adopted in capturing $\mathrm{CO}_{2}$, a good insight of the underlying mechanisms that help to ensure carbon seizure in these systems or their modified forms will help tailor the properties of these adsorbents to suit their applications to other gases. Based on the findings of this review, better $\mathrm{CO}_{2}$ adsorption is often recorded at lower temperatures and higher pressures. Furthermore, as a result of the high solubilities of some of these gases in some ionic liquids, these liquids can be selected, functionalized, and integrated into some choice adsorbents for the basic purpose of trapping any greenhouse gas of interest. This will not only help to reduce cost but will in turn maximize the effectiveness and efficiencies of modern-day greenhouse capture systems. 


\section{Data Availability}

All data used to support the findings of this study are available within the article.

\section{Conflicts of Interest}

The authors are sure that there are no known conflicts of interest as regards the publication of this manuscript.

\section{Acknowledgments}

The management of Covenant University is appreciated for making available online resources and library archives all through the developmental stages of this manuscript.

\section{References}

[1] R. Chatti, A. K. Bansiwal, J. A. Thote et al., "Amine loaded zeolites for carbon dioxide capture: amine loading and adsorption studies," Microporous and Mesoporous Materials, vol. 121, no. 1-3, pp. 84-89, 2009.

[2] H. Yang, Z. Xu, M. Fan et al., "Progress in carbon dioxide separation and capture: a review," Journal of Environmental Sciences, vol. 20, no. 1, pp. 14-27, 2008.

[3] R. V. Siriwardane, M.-S. Shen, E. P. Fisher, and J. A. Poston, "Adsorption of $\mathrm{CO}_{2}$ on molecular sieves and activated carbon," Energy \& Fuels, vol. 15, no. 2, pp. 279-284, 2001.

[4] World meteorological organization (WMO), Greenhouse Gas Bulletin, World meteorological organization (WMO), Geneva, Switzerland, 2014.

[5] Energy Information Administration (EIA), Annual Energy Outlook, Energy Information Administration (EIA), Washington, DC, 2014.

[6] Energy information administration (EIA), International Energy Outlook, Energy Information Administration (EIA), Washington, DC, USA, 2006.

[7] J. D. Figueroa, T. Fout, S. Plasynski, H. McIlvried, and R. D. Srivastava, "Advances in $\mathrm{CO}_{2}$ capture technology-the U.S. department of energy's carbon sequestration program," International Journal of Greenhouse Gas Control, vol. 2, no. 1, pp. 9-20, 2008.

[8] A. A. Olajire, " $\mathrm{CO}_{2}$ capture and separation technologies for end-of-pipe applications-a review," Energy, vol. 35, no. 6, pp. 2610-2628, 2010.

[9] Center For Global Development, "Science daily," 2007, http:// www.sciencedaily.com/releases/2007/11/071114163448.htm.

[10] "California's global warming solutions act", Assembly bill 32, 2006.

[11] " $\$ 45.3$ Billion in US coal-fired power plants cancelled in 2007”, 2009.

[12] U.S. Energy Information Administration (EIA), "Electric power annual 2009," U.S. Energy Information Administration (EIA), Washington, DC, USA, 2009.

[13] U.S. Energy information agency (EIA), "Emissions of greenhouse gases in the United States," 2010, http://www.eia. doe.gov/oiaf/1605/ggrpt/carbon.html.

[14] U.S. Energy Information Administration (EIA), “"Inventory of U.S. greenhouse gas emissions and sinks"” pp. 1990-2008, 2020, http://www.epa.gov/climatechange/emissions/ usinventoryreport.html.
[15] P. Friedlingstein, R. A. Houghton, G. Marland et al., "Update on CO2 emissions," Nature Geoscience, vol. 3, no. 12, pp. 811-812, 2010.

[16] D. Y. C. Leung, G. Caramanna, and M. M. Maroto-Valer, "An overview of current status of carbon dioxide capture and storage technologies," Renewable and Sustainable Energy Reviews, vol. 39, pp. 426-443, 2014.

[17] V. Vakharia, W. Salim, D. Wu et al., "Scale-up of aminecontaining thin-film composite membranes for $\mathrm{CO}_{2}$ capture from flue gas," Journal of Membrane Science, vol. 555, pp. 379-387, 2018.

[18] D. Aaron and C. Tsouris, "Separation of $\mathrm{CO}_{2}$ from flue gas: a review," Separation Science and Technology, vol. 40, no. 1-3, pp. 321-348, 2005.

[19] B. E. Gurkan, J. C. de la Fuente, E. M. Mindrup et al., "Equimolar $\mathrm{CO}_{2}$ absorption by anion-functionalized ionic liquids," Journal of the American Chemical Society, vol. 132, no. 7, pp. 2116-2117, 2010.

[20] F. Bougie and M. C. Iliuta, " $\mathrm{CO}_{2}$ Absorption in aqueous piperazine solutions: experimental study and modeling," Journal of Chemical \& Engineering Data, vol. 56, no. 4, pp. 1547-1554, 2011.

[21] A. Brunetti, F. Scura, G. Barbieri, and E. Drioli, "Membrane technologies for $\mathrm{CO}_{2}$ separation," Journal of Membrane Science, vol. 359, no. 1-2, pp. 115-125, 2010.

[22] Y. Wang, L. Zhao, A. Otto, and M. Robinius, "A review of post-combustion $\mathrm{CO}_{2}$ capture technologies from coal-fired power plants," in Proceedings of the 13th International conference on Greenhouse Gas control technologies, vol. 114, pp. 650-665, Lausanne, Switzerland, 2017.

[23] C. Koytsoumpa, A. Bergins, and E. Kakaras, "“The $\mathrm{CO}_{2}$ economy: review of $\mathrm{CO}_{2}$ capture and reuse technologies"” Journal of Supercritical Fluids, vol. 132, pp. 3-16, 2018.

[24] E.-I. Koytsoumpa, K. Atsonios, K. D. Panopoulos, S. Karellas, E. Kakaras, and J. Karl, "Modelling and assessment of acid gas removal processes in coal-derived SNG production," Applied Thermal Engineering, vol. 74, pp. 128-135, 2015.

[25] D. Jansen, M. Gazzani, G. Manzolini, E. v. Dijk, and M. Carbo, "Pre-combustion $\mathrm{CO}_{2}$ capture," International Journal of Greenhouse Gas Control, vol. 40, pp. 167-187, 2015.

[26] W. L. Theo, J. S. Lim, H. Hashim, A. A. Mustaffa, and W. S. Ho, "Review of pre-combustion capture and ionic liquid in carbon capture and storage," Applied Energy, vol. 183, pp. 1633-1663, 2016.

[27] S. E. Sanni, O. Agboola, O. Fagbiele, E. O. Yusuf, and M. E. Emetere, "Optimization of natural gas treatment for the removal of $\mathrm{CO}_{2}$ and $\mathrm{H}_{2} \mathrm{~S}$ in a novel alkaline-DEA hybrid scrubber," Egyptian Journal of Petroleum, vol. 29, no. 1, pp. 83-94, 2020.

[28] T. Lockwood, "A compararitive review of next-generation carbon capture technologies for coal-fired power plant," Energy Procedia, vol. 114, pp. 2658-2670, 2017.

[29] A. Raza, R. Gholami, R. Rezaee, V. Rasouli, and M. Rabiei, "Significant aspects of carbon capture and storage - a review," Petroleum, vol. 5, no. 4, pp. 335-340, 2019.

[30] E. Blomen, C. Hendriks, and F. Neele, "Capture technologies: improvements and promising developments," Energy Procedia, vol. 1, pp. 1505-1512, 2009.

[31] A. Raza, R. Rezaee, R. Gholami, C. H. Bing, R. Nagarajan, and M. A. Hamid, "A screening criterion for selection of suitable $\mathrm{CO}_{2}$ storage sites," Journal of Natural Gas Science and Engineering, vol. 28, pp. 317-327, 2016. 
[32] A. Sood and S. Vyas, "Carbon capture and sequestration-a review," Earth and Environmental Science, vol. 83, 2017.

[33] S. Bachu, "Screening and ranking of hydrocarbon reservoirs for $\mathrm{CO}_{2}$ storage," in Proceedings of the National conference on carbon sequestration, US department of energy-national energy technology laboratory, Alberta basin, Canada, 2001.

[34] Z. Lei, C. Dai, and B. Chen, "Gas solubility in ionic liquids," Chemical Reviews, vol. 114, no. 2, pp. 1289-1326, 2013.

[35] M. Ramdin, A. Amplianitis, S. Bazhenov et al., "Solubility of $\mathrm{CO}_{2}$ and $\mathrm{CH}_{4}$ in ionic liquids: ideal $\mathrm{CO}_{2} / \mathrm{CH}_{4}$ selectivity," Industrial \& Engineering Chemistry Research, vol. 53, no. 40, pp. 15427-15435, 2014.

[36] J. F. Brennecke and B. E. Gurkan, "Ionic liquids for $\mathrm{CO}_{2}$ capture and emission reduction," Journal of Physical Chemistry Letters, vol. 1, no. 24, pp. 3459-3464, 2010.

[37] J. M. Vicent-Luna, J. J. Gutiérrez-Sevillano, J. A. Anta, and S. Calero, "Effect of room-temperature ionic liquids on $\mathrm{CO} 2$ separation by a $\mathrm{Cu}$-BTC metal-organic framework," The Journal of Physical Chemistry C, vol. 117, no. 40, pp. 20762-20768, 2013.

[38] L. Zhou, J. Fan, and X. Shang, " $\mathrm{CO}_{2}$ capture and separation properties in the ionic liquid 1-n-Butyl-3-Methylimidazolium Nonafluorobutylsulfonate," Materials, vol. 7, no. 5, pp. 3867-3880, 2014.

[39] R. D. Rogers and K. R. Seddon, "Chemistry: ionic liquids-solvents of the future?" Science, vol. 302, no. 5646, pp. 792-793, 2003.

[40] M. Ramdin, T. W. De Loos, and T. J. H. Vlugt, "State-of-theart of $\mathrm{CO}_{2}$ capture with ionic liquids," Industrial \& Engineering Chemistry Research, vol. 51, no. 24, pp. 8149-8177, 2012.

[41] E. D. Bates, R. D. Mayton, I. Ntai, and J. H. Davis, " $\mathrm{CO}_{2}$ capture by a task-specific ionic liquid," Journal of the American Chemical Society, vol. 124, no. 6, pp. 926-927, 2002.

[42] Z.-Z. Yang, Y.-N. Zhao, and L.-N. He, " $\mathrm{CO}_{2}$ chemistry: taskspecific ionic liquids for $\mathrm{CO}_{2}$ capture/activation and subsequent conversion," RSC Advances, vol. 1, no. 4, pp. $545-567,2011$.

[43] A. E. Salako, "Removal of carbon dioxide from natural gas for LNG production," 2005, https://pdfs.semanticscholar. org/37ea/1e656cc310e4797ded37b8781dd06d97694c.pdf.

[44] O. Bolland, " $\mathrm{CO}_{2}$ capture in power plants, Norwegian university of science and technology," 2013, http://www.ivt. ntnu.no/ept/fag/fordypn/tep03/innhold/EP03_Part_4-5_ Absorption.pdf.

[45] A. Kohl and R. Nielsen, "Gas Purification Gulf Publishing Company," Houston, TX, USA, 1997.

[46] R. N. Tennyson and R. P. Schaaf, "Guidelines can help choose proper process for gas-treating plants," Oil Gas Journal, vol. 75, pp. 78-86, 1977.

[47] D. M. D’Alessandro, B. Smit, and J. R. Long, "Carbon dioxide capture: prospects for new materials," Angew. Chemistry, International Edition, vol. 49, pp. 6058-6082, 2010.

[48] M. Ramdin, T. W. De Loos, and T. J. H. Vlugt, "State-of-theArt of $\mathrm{CO}_{2}$ Capture with ionic liquids," Industrial \& Engineering Chemistry Research, vol. 51, no. 24, pp. 8149-8177, 2012.

[49] J. L. Anderson, J. K. Dixon, and J. F. Brennecke, "Solubility of $\mathrm{CO}_{2}, \mathrm{CH}_{4}, \mathrm{C}_{2} \mathrm{H}_{6}, \mathrm{C}_{2} \mathrm{H}_{4}, \mathrm{O}_{2}$, and $\mathrm{N}_{2}$ in 1-Hexyl-3-methylpyridinium bis(trifluoromethylsulfonyl)imide: comparison to other ionic liquids," Accounts of Chemical Research, vol. 40 , no. 11 , p. $1208,2007$.

[50] J. Tang, H. Tang, W. Sun, M. Radosz, and Y. Shen, "Pol$\mathrm{y}$ (ionic liquid)s as new materials for $\mathrm{CO}_{2}$ absorption,"
Journal of Polymer Science Part A: Polymer Chemistry, vol. 43 , no. 22 , p. 5477,2005 a.

[51] J. Tang, H. Tang, W. Sun, H. Plancher, M. Radosz, and Y. Shen, "Poly(ionic liquid)s: a new material with enhanced and fast $\mathrm{CO}_{2}$ absorption," Chemical Communications, vol. 26, p. 3325, 2005 b.

[52] N. Nasirpour, M. Mohammadpourfard, and S. Zeinali Heris, "Ionic liquids: promising compounds for sustainable chemical processes and applications," Chemical Engineering Research and Design, vol. 160, pp. 264-300, 2020.

[53] M. Ramdin, A. Amplianitis, S. Bazhenov et al., "Solubility of $\mathrm{CO}_{2}$ and $\mathrm{CH}_{4}$ in ionic liquids: ideal $\mathrm{CO}_{2} / \mathrm{CH}_{4}$ selectivity," Industrial And Engineering Chemistry Research, vol. 37, 2009.

[54] G. Genduso and I. Pinnau, "Quantification of sorption, diffusion, and plasticization properties of cellulose triacetate films under mixed-gas $\mathrm{CO}_{2} / \mathrm{CH}_{4}$ environment," Journal of Membrane Science, vol. 610, Article ID 118269, 2020.

[55] M. Wang, A. Lawal, P. Stephenson, J. Sidders, and C. Ramshaw, "Post-combustion $\mathrm{CO}_{2}$ capture with chemical absorption: a state-of-the-art review," Chemical Engineering Research and Design, vol. 89, no. 9, pp. 1609-1624, 2011.

[56] G. Puxty, R. Rowland, A. Allport et al., "Carbon dioxide postcombustion capture: a novel screening study of the carbon dioxide absorption performance of 76 amines," Environmental Science \& Technology, vol. 43, no. 16, pp. 6427-6433, 2009.

[57] C.-H. Yu, C.-H. Huang, and C.-S. Tan, "A review of $\mathrm{CO}_{2}$ capture by absorption and adsorption," Aerosol and Air Quality Research, vol. 12, no. 5, pp. 745-769, 2012.

[58] R. Idem, M. Wilson, P. Tontiwachwuthikul et al., "Pilot plant studies of the $\mathrm{CO}_{2}$ Capture performance of aqueous MEA and mixed MEA/MDEA solvents at the university of Regina $\mathrm{CO}_{2}$ Capture technology development plant and the boundary dam $\mathrm{CO}_{2}$ capture demonstration plant," Industrial \& Engineering Chemistry Research, vol. 45, no. 8, pp. 2414-2420, 2006.

[59] Q. Zhuang, R. Pomalis, L. Zheng, and B. Clements, "Ammoniabased carbon dioxide capture technology: issues and solutions," Energy Procedia, vol. 4, pp. 1459-1470, 2011.

[60] " $\mathrm{CO}_{2}$ Capture Project", 2018. http://www.CO2captureproject. com.

[61] E. Knapik, P. Kosowski, and J. Stopa, "Cryogenic liquefaction and separation of $\mathrm{CO}_{2}$ using nitrogen removal unit cold energy," Chemical Engineering Research and Design, vol. 131, pp. 66-79, 2018.

[62] J. Xu and W. Lin, "A $\mathrm{CO}_{2}$ cryogenic capture system for flue gas of an LNG-fired power plant," International Journal of Hydrogen Energy, vol. 42, no. 29, pp. 18674-18680, 2017.

[63] W. Lin, X. Xiong, and A. Gu, "Optimization and thermodynamic analysis of a cascade PLNG (pressurized liquefied natural gas) process with $\mathrm{CO}_{2}$ cryogenic removal," Energy, vol. 161, pp. 870-877, 2018.

[64] A. Ali, K. Maqsood, A. Redza, K. Hii, A. B. M. Shariff, and S. Ganguly, "Performance enhancement using multiple cryogenic desublimation based pipeline network during dehydration and carbon capture from natural gas," Chemical Engineering Research and Design, vol. 109, pp. 519-531, 2016.

[65] C. Song, Q. Liu, N. Ji, S. Deng, J. Zhao, and Y. Kitamura, "Advanced cryogenic $\mathrm{CO}_{2}$ capture process based on Stirling coolers by heat integration," Applied Thermal Engineering, vol. 114, pp. 887-895, 2017.

[66] H. Tan, Q. Chen, T. Chen, Z. Wei, and H. Liu, " $\mathrm{CO}_{2} / \mathrm{CH}_{4}$ separation using flexible microporous organic polymers with 
expansion/shrinkage transformations during adsorption/ desorption processes," vol. 391, Article ID 123521, 2020.

[67] W. Huang, X. Zhou, Q. Xia et al., "Preparation and adsorption performance of $\mathrm{GrO} @ \mathrm{Cu}-\mathrm{BTC}$ for separation of $\mathrm{CO}_{2} / \mathrm{CH}_{4}$," Industrial \& Engineering Chemistry Research, vol. 53, no. 27, pp. 11176-11184, 2014.

[68] G. T. Rochelle, "Amine scrubbing for $\mathrm{CO}_{2}$ capture," Science, vol. 325, no. 5948, pp. 1652-1654, 2009.

[69] S. Rackley, "Carbon Capture and Storage," pp. 9780128120415, Gulf Professional Publishing, Houston, TX, USA, 2009.

[70] J.-R. Li, R. J. Kuppler, and H.-C. Zhou, "Selective gas adsorption and separation in metal-organic frameworks," Chemical Society Reviews, vol. 38, no. 5, pp. 1477-1504, 2009.

[71] T. Duren, Y.-S. Bae, and R. Q. Snurr, "Using molecular simulation to characterise metal-organic frameworks for adsorption applications," Chemical Society Reviews, vol. 38, no. 1, pp. 1237-1247, 2009.

[72] S. Kitagawa, R. Kitaura, and S. Noro, "Functional porous coordination polymers," Angewandte Chemie International Edition, vol. 43, no. 18, pp. 2334-2375, 2004.

[73] O. M. Yaghi, M. O’Keeffe, N. W. Ockwig, H. K. Chae, M. Eddaoudi, and J. Kim, "Reticular synthesis and the design of new materials"' Nature, vol. 423, no. 12, pp. 705-714, 2003.

[74] K. Sumida, D. L. Rogow, J. A. Mason et al., "Carbon dioxide capture in metal-organic frameworks," Chemical Reviews, vol. 112, no. 2, pp. 724-781, 2011.

[75] K. C. Stylianou and W. L. Queen, "Recent advances in carbon capture with metal-organic frameworks," CHIMIA International Journal for Chemistry, vol. 69, no. 5, pp. 274-283, 2015.

[76] Z. Zhang, Z.-Z. Yao, S. Xiang, and B. Chen, "Perspective of microporous metal-organic frameworks for $\mathrm{CO} 2$ capture and separation," Energy \& Environmental Science, vol. 7, no. 9, pp. 2868-2899, 2014.

[77] J. Wang, L. Huang, R. Yang et al., "Recent advances in solid sorbents for CO2capture and new development trends," Energy Environ. Sci.vol. 7, no. 11, pp. 3478-3518, 2014.

[78] J.-R. Li, J. Sculley, and H.-C. Zhou, "Metal-organic frameworks for separations," Chemical Reviews, vol. 112, no. 2, pp. 869-932, 2011.

[79] A. L. Dzubak, L.-C. Lin, J. A. Kim, R. Poloni et al., "Ab initio carbon capture in open-site metal-organic frameworks," Nature Chemistry, vol. 4, no. 10, pp. 810-816, 2012.

[80] X. Kong, E. Scott, W. Ding, J. A. Mason, J. R. Long, and J. A. Reimer, "CO2 dynamics in a metal-organic framework with open metal sites," Journal of the American Chemical Society, vol. 134, no. 35, pp. 14341-14344, 2012.

[81] A. O. Yazaydın, R. Q. Snurr, M. D. LeVan et al., "Screening of metal-organic frameworks for carbon dioxide capture from flue gas using a combined experimental and modeling approach," Journal of the American Chemical Society, vol. 131, no. 51, pp. 18198-18199, 2009.

[82] P. Canepa, C. A. Arter, E. M. Conwill et al., "Highthroughput screening of small-molecule adsorption in MOF," Journal of Materials Chemistry A, vol. 1, no. 43, pp. 13597-13604, 2013.

[83] X.-J. Hou, P. He, H. Li, and X. Wang, "Understanding the adsorption mechanism of $\mathrm{C}_{2} \mathrm{H}_{2}, \mathrm{CO}_{2}$, and $\mathrm{CH}_{4}$ in isostructural metal-organic frameworks with coordinatively unsaturated metal sites," The Journal of Physical Chemistry C, vol. 117, no. 6, pp. 2824-2834, 2013.
[84] C. R. Wade and M. Dincă, "Investigation of the synthesis, activation, and isosteric heats of $\mathrm{CO}_{2}$ adsorption of the isostructural series of metal-organic frameworks M3(BTC)2 $(\mathrm{M}=\mathrm{Cr}, \mathrm{Fe}, \mathrm{Ni}, \mathrm{Cu}, \mathrm{Mo}, \mathrm{Ru})$, , Dalton Transactions, vol. 41, no. 26, pp. 7931-7938, 2012.

[85] P. L. Llewellyn, S. Bourrelly, C. Serre et al., "High uptakes of $\mathrm{CO}_{2}$ and $\mathrm{CH}_{4}$ in mesoporous metal organic frameworks MIL100 and MIL-101," Langmuir, vol. 24, no. 14, pp. 7245-7250, 2008.

[86] C. P. De Weireld, P. Rumori, and G. T. Palomino, "Carbon dioxide adsorption on MIL-100(M) $(\mathrm{M}=\mathrm{Cr}, \mathrm{V}, \mathrm{Sc})$ metalorganic frameworks: IR spectroscopic and thermodynamic studies," Microporous and Mesoporous Materials, vol. 190, pp. 234-239, 2014.

[87] S. Chaemchuen, K. Zhou, N. A. Kabir et al., “Tuning metal sites of DABCO MOF for gas purification at ambient conditions," Microporous and Mesoporous Materials, vol. 201, pp. 277-285, 2015.

[88] L. Li, J. Yang, J. Li, Y. Chen, and J. Li, "Separation of $\mathrm{CO}_{2} /$ $\mathrm{CH}_{4}$ and $\mathrm{CH}_{4} / \mathrm{N}_{2}$ mixtures by M/DOBDC: a detailed dynamic comparison with MIL-100(Cr) and activated carbon," Microporous and Mesoporous Materials, vol. 198, pp. 236246, 2014.

[89] A. Torrisi, R. G. Bell, and C. Mellot-Draznieks, "Predicting the impact of functionalized ligands on $\mathrm{CO}_{2}$ adsorption in MOFs: a combined DFT and Grand Canonical Monte Carlo study," Microporous and Mesoporous Materials, vol. 168, pp. 225-238, 2013.

[90] Q. Lin, T. Wu, S.-T. Zheng, X. Bu, and P. Feng, "SingleWalled polytetrazolate metal-organic channels with high density of open nitrogen-donor sites and gas uptake," Journal of the American Chemical Society, vol. 134, no. 2, pp. 784-787, 2011.

[91] E. Keceli, M. Hemgesberg, R. Grünker et al., "A series of amide functionalized isoreticular metal organic frameworks," Microporous and Mesoporous Materials, vol. 194, pp. 115-125, 2014.

[92] Y. Yang, R. Lin, L. Ge et al., "Synthesis and characterization of three amino-functionalized metal-organic frameworks based on the 2-aminoterephthalic ligand," Dalton Transactions, vol. 44, no. 17, pp. 8190-8197, 2015.

[93] R. Vaidhyanathan, S. S. Iremonger, K. W. Dawson, and G. K. H. Shimizu, "An amine-functionalized metal organic framework for preferential $\mathrm{CO}_{2}$ adsorption at low pressures," Chemical Communications, vol. 35, no. 35, pp. 5230-5232, 2009.

[94] S. Xiong, Y. Gong, H. Wang et al., "A new tetrazolate zeolitelike framework for highly selective $\mathrm{CO}_{2} / \mathrm{CH}_{4}$ and $\mathrm{CO}_{2} / \mathrm{N}_{2}$ separation," Chemical Communications, vol. 50, no. 81, pp. 12101-12104, 2014.

[95] W.-Y. GaoW. Yan et al., "Porous double-walled metal triazolate framework based upon a bifunctional ligand and a pentanuclear zinc cluster exhibiting selective $\mathrm{CO}_{2}$ uptake," Inorganic chemistry, vol. 51, no. 8, pp. 4423-4425, 2012.

[96] J. Liu, P. K. Thallapally, B. P. McGrail, D. R. Brown, and J. Liu, "Progress in adsorption-based $\mathrm{CO}_{2}$ capture by metalorganic frameworks," Chemical Society Reviews, vol. 41, no. 6, pp. 2308-2322, 2012.

[97] Z. Wang, K. K. Tanabe, and S. M. Cohen, "Accessing postsynthetic modification in a series of metal-organic frameworks and the influence of framework topology on reactivity," Inorganic Chemistry, vol. 48, no. 1, pp. 296-306, 2008. 
[98] H. Deng, C. J. Doonan, H. Furukawa et al., "Multiple functional groups of varying ratios in metal-organic frameworks," Science, vol. 12, no. 327, pp. 846-850, 2010.

[99] T. Watabe, Y. Nishizaka, S. Kazama, and K. Yogo, "Development of amine-modified solid sorbents for postcombustion $\mathrm{CO}_{2}$ capture," Energy Procedia, vol. 37, pp. 199-204, 2013.

[100] T. Watabe and K. Yogo, "Isotherms and isosteric heats of adsorption for $\mathrm{CO}_{2}$ in amine-functionalized mesoporous silicas," Separation and Purification Technology, vol. 120, pp. 20-23, 2013.

[101] T. Prenzel, M. Wilhelm, and K. Rezwan, "Tailoring amine functionalized hybrid ceramics to control $\mathrm{CO}_{2}$ adsorption," Chemical Engineering Journal, vol. 235, pp. 198-206, 2014.

[102] M. Auta and B. H. Hameed, "Adsorption of carbon dioxide by diethanolamine activated alumina beads in a fixed bed," Chemical Engineering Journal, vol. 253, pp. 350-355, 2014.

[103] R. K. Motkuri, J. Liu, C. A. Fernandez, S. K. Nune, P. Thallapally, and B. P. McGrail, "Metal-organic frameworks - synthesis and applications," in Industrial Catalysis and Separations: innovations for process intensification, pp. 61-103, Apple Academic Press Inc, Waretown, NJ, USA, 2017.

[104] S. M. Cohen, "Postsynthetic methods for the functionalization of metal-organic frameworks," Chemical Reviews, vol. 112, no. 2, pp. 970-1000, 2011.

[105] W. R. Lee, S. Y. Hwang, D. W. Ryu et al., "Diaminefunctionalized metal-organic framework: exceptionally high $\mathrm{CO} 2$ capacities from ambient air and flue gas, ultrafast $\mathrm{CO}_{2}$ uptake rate, and adsorption mechanism," Energy Environment Science, vol. 7, no. 2, pp. 744-751, 2014.

[106] T. M. McDonald, W. R. Lee, J. A. Mason, B. M. Wiers, C. S. Hong, and J. R. Long, "Capture of carbon dioxide from air and flue gas in the alkylamine-appended metal-organic framework mmen- $\mathrm{Mg}_{2}$ (dobpdc)," Journal of the American Chemical Society, vol. 134, no. 16, pp. 7056-7065, 2012.

[107] V. Chernikova, O. Shekhah, Y. Belmabkhout, and M. Eddaoudi, "Nanoporous fluorinated metal-organic framework-based membranes for $\mathrm{CO}_{2}$ capture," ACS Applied Nano Materials, vol. 47, 2015.

[108] L. Li, S. Tang, C. Wang et al., "High gas storage capacities and stepwise adsorption in a UiO type metal-organic framework incorporating Lewis basic bipyridyl sites," Chemical Communications, vol. 50, no. 18, pp. 2304-2307, 2014.

[109] J. Cai, X. Rao, Y. He et al., "A highly porous NbO type metalorganic framework constructed from an expanded tetracarboxylate," Chemical Communications, vol. 50, no. 13, pp. 1552-1554, 2014.

[110] M. Taddei, F. Costantino, F. Marmottini, A. Comotti, P. Sozzani, and R. Vivani, "The first route to highly stable crystalline microporous zirconium phosphonate metal-organic frameworks," Chemical Communication, vol. 50, no. 94, pp. 14831-14834, 2014.

[111] M. Taddei, F. Costantino, A. Ienco, A. Comotti, P. V. Dau, and S. M. Cohen, "Synthesis, breathing, and gas sorption study of the first isoreticular mixed-linker phosphonate based metal-organic frameworks," Chemical Communications, vol. 49, no. 13, pp. 1315-1317, 2013.

[112] Y. Peng, G. Srinivas, C. E. Wilmer et al., "Simultaneously high gravimetric and volumetric methane uptake characteristics of the metal-organic framework NU-111," Chemical Communications, vol. 49, no. 29, pp. 2992-2994, 2013.
[113] J. Kim, Y.-R. Lee, and W.-S. Ahn, "Dry-gel conversion synthesis of Cr-MIL-101 aided by grinding: high surface area and high yield synthesis with minimum purification," Chemical Communications, vol. 49, no. 69, pp. 7647-7649, 2013.

[114] Y. He, H. Furukawa, C. Wu, M. O’Keeffe, R. Krishna, and B. Chen, "Low-energy regeneration and high productivity in a lanthanide-hexacarboxylate framework for high-pressure $\mathrm{CO}_{2}-\mathrm{CH}_{4}-\mathrm{H}_{2}$ separation," Chemical Communications, vol. 49, no. 60, pp. 6773-6775, 2013.

[115] X. Wu, M. Niknam Shahrak, B. Yuan, and S. Deng, "Synthesis and characterization of zeolitic imidazolate framework ZIF-7 for $\mathrm{CO}_{2}$ and $\mathrm{CH}_{4}$ separation," Microporous and Mesoporous Materials, vol. 190, pp. 189-196, 2014.

[116] G. Yang, J. A. Santana, M. E. Rivera-Ramos et al., “A combined experimental and theoretical study of gas sorption on nanoporous silver triazolato metal-organic frameworks," Microporous and Mesoporous Materials, vol. 183, pp. 62-68, 2014.

[117] E. Deniz, F. Karadas, H. A. Patel, S. Aparicio, C. T. Yavuz, and M. Atilhan, "A combined computational and experimental study of high pressure and supercritical $\mathrm{CO}_{2}$ adsorption on Basolite MOFs," Microporous and Mesoporous Materials, vol. 175, pp. 34-42, 2013.

[118] S. Ye, X. Jiang, L.-W. Ruan et al., "Post-combustion $\mathrm{CO}_{2}$ capture with the HKUST-1 and MIL-101(Cr) metal-organic frameworks: adsorption, separation and regeneration investigations," Microporous and Mesoporous Materials, vol. 179, pp. 191-197, 2013.

[119] N. C. Burtch, H. Jasuja, D. Dubbeldam, and K. S. Walton, "Molecular-level insight into unusual low pressure $\mathrm{CO}_{2}$ affinity in pillared metal-organic frameworks," Journal of the American Chemical Society, vol. 135, no. 19, pp. 7172-7180, 2013.

[120] W.-Y. Gao, T. Pham, K. A. Forrest et al., "The local electric field favours more than exposed nitrogen atoms on $\mathrm{CO}_{2}$ capture: a case study on the rht-type MOF platform: a case study on the rht-type MOF platform," Chemical Communications, vol. 51, no. 47, pp. 9636-9639, 2015.

[121] D. Wang, B. Liu, S. Yao et al., "A polyhedral metal-organic framework based on the super molecular building block strategy exhibiting high performance for carbon dioxide capture and separation of light hydrocarbons," Chemical Communications, vol. 9, 2015.

[122] S. K. Elsaidi, M. H. Mohamed, H. T. Schaef et al., "Hydrophobic pillared square grids for selective removal of $\mathrm{CO}_{2}$ from simulated flue gas," Chemical Communications, vol. 9, 2015.

[123] Y.-W. Li, J. Xu, D.-C. Li, J.-M. Dou, T.-L. Yan, and X.-H. Bu, "Two microporous MOFs constructed from different metal cluster SBUs for selective gas adsorption," Chemical Communications, vol. 51, no. 75, pp. 14211-14214, 2015.

[124] Y.-S. Bae, J. Liu, C. E. Wilmer et al., "The effect of pyridine modification of Ni-DOBDC on $\mathrm{CO}_{2}$ capture under humid conditions," Chem. Commun.vol. 50, no. 25, pp. 3296-3298, 2014.

[125] F. Wang, H.-R. Fu, Y. Kang, and J. Zhang, "A new approach towards zeolitic tetrazolate-imidazolate frameworks (ZTIFs) with uncoordinated $\mathrm{N}$-heteroatom sites for high $\mathrm{CO}_{2}$ uptake (ZTIFs) with uncoordinated $\mathrm{N}$-heteroatom sites for high $\mathrm{CO}_{2}$ uptake"” Chem. Commun.vol. 50, no. 81, pp. 12065-12068, 2014.

[126] S. Xiong, Y. Gong, H. Wang et al., "A new tetrazolate zeolitelike framework for highly selective $\mathrm{CO}_{2} / \mathrm{CH}_{4}$ and $\mathrm{CO}_{2} / \mathrm{N}_{2}$ 
separation," Chemical Communication, vol. 50, no. 81, pp. 12101-12104, 2014.

[127] C. Song, Y. He, B. Li et al., "Enhanced $\mathrm{CO}_{2}$ sorption and selectivity by functionalization of a $\mathrm{NbO}$-type metal-organic framework with polarized benzothiadiazole moieties," Chemical Communnication, vol. 50, no. 81, pp. 12105-12108, 2014.

[128] C. H. Lau, R. Babarao, and M. R. Hill, "A route to drastic increase of $\mathrm{CO}_{2}$ uptake in $\mathrm{Zr}$ metal organic framework UiO66," Chemical Communications, vol. 49, pp. 3634-3636, 2013.

[129] J. Luo, J. Wang, G. Li, Q. Huo, and Y. Liu, “Assembly of a unique octa-nuclear copper cluster-based metal-organic framework with highly selective $\mathrm{CO}_{2}$ adsorption over $\mathrm{N}_{2}$ and $\mathrm{CH}_{4}$," Chemical Communications, vol. 49, no. 97, pp. 11433-11435, 2013.

[130] R. Sabouni, H. Kazemian, and S. Rohani, "Carbon dioxide adsorption in microwave-synthesized metal organic framework CPM-5: equilibrium and kinetics study," Microporous and Mesoporous Materials, vol. 175, pp. 85-91, 2013.

[131] L. Ding and A. O. Yazaydin, "The effect of $\mathrm{SO}_{2}$ on $\mathrm{CO}_{2}$ capture in zeolitic imidazolate frameworks," Physical Chemistry Chemical Physics, vol. 15, no. 28, pp. 11856-11861, 2013.

[132] Z.-H. Xuan, D.-S. Zhang, T.-L. Chang, and X.-H. Bu, "Targeted structure modulation of pillar-layered metal-organic frameworks for $\mathrm{CO}_{2}$ capture," Inorganic Chemistry, vol. 53, no. 17, pp. 8985-8990, 2014.

[133] R.-R. Cheng, S.-X. Shao, H.-H. Wu, Y.-F. Niu, J. Han, and X.-L. Zhao, "A dual functional porous NbO-type metalorganic framework decorated with acylamide groups for selective sorption and catalysis," Inorganic Chemistry Communications, vol. 46, pp. 226-228, 2014.

[134] T. Li, D.-L. Chen, J. E. Sullivan, M. T. Kozlowski, J. K. Johnson, and N. L. Rosi, "Systematic modulation and enhancement of $\mathrm{CO}_{2}: \mathrm{N}_{2}$ selectivity and water stability in an isoreticular series of bio-MOF-11 analogues," Chemical Science, vol. 4, no. 4, pp. 1746-1755, 2013.

[135] R. S. Bhavsar, T. Mitra, D. J. Adams, A. I. Cooper, and P. M. Budd, "Ultrahigh-permeance PIM-1 based thin film nanocomposite membranes on PAN supports for $\mathrm{CO}_{2}$ separation," Journal of Membrane Science, vol. 564, pp. 878-886, 2018.

[136] P. M. Budd, E. S. Elabas, B. S. Ghanem et al., "Solutionprocessed, organophilic membrane derived from a polymer of intrinsic microporosity," Advanced Materials, vol. 16, no. 5, pp. 456-459, 2004.

[137] I. Borisov, D. Bakhtin, J. M. Luque-Alled et al., "Synergistic enhancement of gas selectivity in thin film composite membranes of PIM-1," Journal of Materials Chemistry A, vol. 7, no. 11, pp. 6417-6430, 2019.

[138] A. K. Sekizkardes, V. A. Kusuma, J. S. McNally et al., "Microporous polymeric composite membranes with advanced film properties: pore intercalation yields excellent $\mathrm{CO}_{2}$ separation performance," Journal of Materials Chemistry A, vol. 6, no. 45, pp. 22472-22477, 2018.

[139] M. Hopkinson, M. D. Nothling, P. A. Webley, J. Jin, Q. Fu, and G. G. Qiao, "High-throughput $\mathrm{CO}_{2}$ capture using PIM$1 @$ MOF based thin film composite membranes," Chemical Engineering Journal, vol. 125328, p. 386, 2020.

[140] C. Z. Liang, J. T. Liu, J.-Y. Lai, and T.-S. Chung, "Highperformance multiple-layer PIM composite hollow fiber membranes for gas separation," Journal of Membrane Science, vol. 563, pp. 93-106, 2018.

[141] R. R. Tiwari, J. Jin, B. D. Freeman, and D. R. Paul, "Physical aging, $\mathrm{CO}_{2}$ sorption and plasticization in thin films of polymer with intrinsic microporosity (PIM-1)," Journal of Membrane Science, vol. 537, pp. 362-371, 2017.

[142] R. Swaidan, B. Ghanem, E. Litwiller, and I. Pinnau, "Physical aging, plasticization and their effects on gas permeation in rigid polymers of intrinsic microporosity," Macromolecules, vol. 48, no. 18, pp. 6553-6561, 2015.

[143] A. Mahmoudi, M. Zargar, and V. Zargar, " $\mathrm{CO}_{2} / \mathrm{CH}_{4}$ separation through a novel commercializable three-phase PEBA/ PEG/NaX nanocomposite membrane," Journal of Industrial and Engineering Chemistry, vol. 23, pp. 238-242, 2015.

[144] A. Jomekian, B. Bazooyar, R. M. Behbahani, T. Mohammadi, and A. Kargari, "Ionic liquid-modified Pebax 1657 membrane filled by ZIF-8 particles for separation of $\mathrm{CO}_{2}$ from $\mathrm{CH}_{4}, \mathrm{~N}_{2}$ and $\mathrm{H}_{2}$," Journal of Membrane Science, vol. 524, pp. 652-662, 2017.

[145] P. D. Sutrisna, J. Hou, H. Lia, Y. Zhang, and V. Chena, "Improved operational stability of Pebax-based gas separation membranes with ZIF-8: a comparative study of flat sheet and composite hollow fibre membranes," Journal of Membrane Science, vol. 524, pp. 266-279, 2016.

[146] F. A. Beni and M. N. Shahrak, "Alkali metals-promoted capacity of ZIF-8 and ZIF-90 for carbon capturing: a molecular simulation study”," Polyhedron, vol. 114338, p. 178, 2020.

[147] W. Zheng, R. Ding, K. Yang, Y. Dai, X. Yan, and G. He, “ZIF8 nanoparticles with tunable size for enhanced $\mathrm{CO}_{2}$ capture of Pebax based MMMs"' Separation and Purification Technology, vol. 214, pp. 114-119, 2018.

[148] https://www.fastcompany.com/90539896/coating-seeds-inthis-microfungus-makes-plants-into-carbon-capturemachines.

[149] L. Lu, Z. Huang, G. H. Rau, and Z. J. Ren, "Microbial electrolytic carbon capture for carbon negative and energy positive wastewater treatment," Environmental Science \& Technology, vol. 49, no. 13, pp. 8193-8201, 2015.

[150] A. C. Mitchel, K. Dideriksen, L. H. Spangler, A. B. Cunningham, and R. Gerlach, "Microbially enhanced carbon capture and storage by mineral-trapping and solubility-trapping," Environmental Science and Technology, vol. 44, no. 13, pp. 5270-5276, 2010.

[151] L. E. Bruce, C. Douglas, C. Shaoan et al., “"Microbial electrolysis cells for high yield hydrogen gas production from organic matter"' Environmental Science and Technology, vol. 42, no. 23, pp. 8630-8640, 2008.

[152] N. Konduru, P. Lindner, and N. M. Assaf-Anid, "Curbing the greenhouse effect by carbon dioxide adsorption with Zeolite 13X," AIChE Journal, vol. 53, no. 12, p. 3137, 2007.

[153] J. Mere, J. M. Clausse, and F. Meunier, “"Experimental investigation on $\mathrm{CO}_{2}$ postcombustion capture by indirect thermal swing adsorption using $13 \mathrm{X}$ and $5 \mathrm{~A}$ zeolites"' Industrial Engineering and Chemistry Research, vol. 47, no. 1, p. 209, 2008.

[154] S. Kumara, R. Srivastava, and J. Koh, “"Utilization of zeolites as $\mathrm{CO}_{2}$ capturing agents: advances and future perspectives," Journal of Utilization, vol. 101251, p. 41, 2020.

[155] N. Gargiulo, D. Caputo, and C. Colella, "Preparation and characterization of polyethylenimine-modified mesoporous silicas as $\mathrm{CO}_{2}$ sorbents," in Studies in Surface Science and Catalysis, R. Xu, Z. Gao, J. Chen, and W. Yan, Eds., , pp. 1938-1943, Elsevier, 2007. 
[156] N. Gargiulo, A. Peluso, P. Aprea, F. Pepe, and D. Caputo, " $\mathrm{CO}_{2}$ adsorption on polyethylenimine-functionalized SBA15 mesoporous silica: isotherms and modeling," Journal of Chemical \& Engineering Data, vol. 59, no. 3, pp. 896-902, 2014.

[157] J. Yang, J. Li, W. Wang, L. Li, and J. Li, “Adsorption of $\mathrm{CO}_{2}$, $\mathrm{CH}_{4}$, and $\mathrm{N} 2$ on 8-, 10-, and 12-membered ring hydrophobic microporous high-silica zeolites: DDR, silicalite-1, and beta," Industrial \& Engineering Chemistry Research, vol. 52, no. 50, pp. 17856-17864, 2013.

[158] L. Grajciar, J. Čejka, A. Zukal, C. Otero, G. Turnes, and P. Nachtigall, "Controlling the adsorption enthalpy of $\mathrm{CO}_{2}$ in zeolites by framework topology and composition," ChemSusChem, vol. 5, no. 10, pp. 2011-2022, 2012.

[159] W. Jeong and J. Kim, "Understanding the mechanisms of $\mathrm{CO}_{2}$ adsorption enhancement in pure silica zeolites under humid conditions," The Journal of Physical Chemistry C, vol. 120, no. 41, pp. 23500-23510, 2016.

[160] A. R. Millward and O. M. Yaghi, "Metal-Organic frameworks with exceptionally high capacity for storage of carbon dioxide at room temperature," Journal of the American Chemical Society, vol. 127, no. 51, pp. 17998-17999, 2005.

[161] V. S. Balashankar and A. Rajendran, "Process optimizationbased screening of zeolites for post-combustion $\mathrm{CO}_{2}$ capture by vacuum swing adsorption," ACS Sustainability and Chemical Engineering, vol. 7, no. 21, pp. 17747-17755, 2019.

[162] D. Wang, C. Sentorun-Shalaby, X. Ma, and C. Song, "Highcapacity and low-cost carbon-based molecular basket sorbent for $\mathrm{CO}_{2}$ capture from flue gas," Energy \& Fuels, vol. 25, no. 1, pp. 456-458, 2011.

[163] J. Zhang, R. Singh, and P. A. Webley, "Alkali and alkalineearth cation exchanged chabazite zeolites for adsorption based $\mathrm{CO}_{2}$ capture," Microporoporous and Mesoporous Materials, vol. 111, no. 1-3, pp. 478-487, 2008.

[164] J. A. Dunne, M. Rao, S. Sircar, R. J. Gorte, and A. L. Myers, "Calorimetric heats of adsorption and adsorption isotherms. 2. $\mathrm{O}_{2}, \mathrm{~N}_{2}, \mathrm{Ar}, \mathrm{CO}_{2}, \mathrm{CH}_{4}, \mathrm{C}_{2} \mathrm{H}_{6}$, and $\mathrm{SF}_{6}$ on NaX, H-ZSM-5, and Na-ZSM-5 zeolites," Langmuir, vol. 12, no. 24, pp. 5896-5904, 1996.

[165] R. M. Barrer and R. M. Gibbons, "Zeolitic carbon dioxide: energetics and equilibria in relation to exchangeable cations in faujasite," Transactions of the Faraday Society, vol. 61, pp. 948-961, 1965.

[166] P. J. E. Harlick and F. H. Tezel, "An experimental adsorbent screening study for $\mathrm{CO}_{2}$ removal from $\mathrm{N}_{2}$," Micropororous and Mesoporous Matererials, vol. 76, no. 1-3, pp. 71-79, 2004.

[167] R. Hernandez-Huesca, L. Diaz, and G. Aguilar-Armenta, "Adsorption equilibria and kinetics of $\mathrm{CO}_{2}, \mathrm{CH}_{4}$ and $\mathrm{N}_{2}$ in natural zeolites"' Separation and Purification Technology, vol. 15, pp. 163-173, 1950.

[168] T. D. Pham, R. Xiong, S. I. Sandler, and R. F. Lobo, "Experimental and computational studies on the adsorption of $\mathrm{CO}_{2}$ and $\mathrm{N}_{2}$ on pure silica zeolites," Microporous and Mesoporous Materials, vol. 185, pp. 157-166, 2014.

[169] P. J. E. Harlick and F. H. Tezel, "Adsorption of carbon dioxide, methane and nitrogen: pure and binary mixture adsorption for ZSM-5 with $\mathrm{SiO}_{2} / \mathrm{Al}_{2} \mathrm{O} 3$ ratio of 280," Separation and Purification Technology, vol. 33, no. 2, pp. 199-210, 2003.

[170] G. Calleja, A. Jimenez, J. Pau, L. Domínguez, and P. Pérez, "Multicomponent adsorption equilibrium of ethylene, propane, propylene and $\mathrm{CO}_{2}$ on $13 \mathrm{X}$ zeolite," Gas Separation \& Purification, vol. 8, no. 4, pp. 247-256, 1994.
[171] J. A. Dunne, R. Mariwala, M. Rao, S. Sircar, R. J. Gorte, and A. L. Myers, "Calorimetric heats of adsorption and adsorption isotherms. 1. $\mathrm{O}_{2}, \mathrm{~N}_{2}, \mathrm{Ar}, \mathrm{CO}_{2}, \mathrm{CH}_{4}, \mathrm{C}_{2} \mathrm{H}_{6}$, and $\mathrm{SF}_{6}$ on silicalite," Langmuir, vol. 12, no. 24, pp. 5888-5895, 1996b.

[172] S. Cavenati, C. A. Grande, and A. E. Rodrigues, “Adsorption equilibrium of methane, carbon dioxide, and nitrogen on zeolite 13X at high pressures," Journal Of Chemical And Engineering Data, vol. 1095, p. 49, 2004.

[173] P. D. Jadhav, R. V. Chatti, R. B. Biniwale, N. K. Labhsetwar, S. Devotta, and S. S. Rayalu, "Monoethanol amine modified zeolite $13 \mathrm{X}$ for $\mathrm{CO}_{2}$ adsorption at different temperatures," Energy \& Fuels, vol. 21, no. 6, pp. 3555-3559, 2007.

[174] Y. Cho, J.-Y. Lee, A. D. Bokare et al., "LiOH-embedded zeolite for carbon dioxide capture under ambient conditions," Journal of Industrial and Engineering Chemistry, 2014.

[175] M. Mohamedali, D. Nath, H. Ibrahim, and A. Henni, "Review of recent developments in $\mathrm{CO}_{2}$ capture using solid materials: metal organic frameworks (MOFs)," vol. 6, pp. 115-154, 2016.

[176] S. E. Sanni, O. Agboola, O. Agboola, R. E. Sadiku, M. E. Emetere, and M. E. Emetere, "Nature of graphene, its chemical structure, composites, synthesis, properties, and applications," Handbook of Graphene, vol. 19, pp. 613-636, 2019.

[177] S.-M. Hong, S. H. Kim, and K. B. Lee, "Adsorption of carbon dioxide on 3-aminopropyl-triethoxysilane modified graphite oxide," Energy \& Fuels, vol. 27, no. 6, pp. 3358-3363, 2013.

[178] M. Asai, T. Ohba, T. Iwanaga et al., "Marked adsorption irreversibility of graphitic Nanoribbons for $\mathrm{CO}_{2}$ and $\mathrm{H}_{2} \mathrm{O}$," Journal of the American Chemical Society, vol. 133, no. 38, pp. 14880-14883, 2011.

[179] L.-Y. Meng and S.-J. Park, "Effect of exfoliation temperature on carbon dioxide capture of graphene nanoplates," Journal of Colloid and Interface Science, vol. 386, no. 1, pp. 285-290, 2012.

[180] F. Li, X. Jiang, J. Zhao, and S. Zhang, "Graphene oxide: a promising nanomaterial for energy and environmental applications," Nano Energy, vol. 16, pp. 488-515, 2015.

[181] S. Gadipelli and Z. X. Guo, "Graphene-based materials: synthesis and gas sorption, storage and separation," Progress in Materials Science, vol. 69, pp. 1-60, 2015.

[182] A. T. Najafabadi, "Emerging applications of graphene and its derivatives in carbon capture and conversion: current status and future prospects," Renewable and Sustainable Energy Reviews, vol. 41, pp. 1515-1545, 2015.

[183] K. C. Kemp, V. Chandra, M. Saleh, and K. S. Kim, "Reversible $\mathrm{CO}_{2}$ adsorption by an activated nitrogen doped graphene/polyaniline material," Nanotechnology, vol. 24, Article ID 235703, 2013.

[184] J. Oh, Y.-H. Mo, V.-D. Le et al., "Borane-modified graphenebased materials as $\mathrm{CO}_{2}$ adsorbents," Carbon, vol. 79, pp. 450-456, 2014.

[185] W. Li, X. Jiang, H. Yang, and Q. Liu, "Solvothermal synthesis and enhanced $\mathrm{CO}_{2}$ adsorption ability of mesoporous graphene oxide- $\mathrm{ZnO}$ nanocomposite," Applied Surface Science, vol. 356, pp. 812-816, 2015.

[186] S. Chowdhury, G. K. Parshetti, and R. Balasubramanian, "Post-combustion $\mathrm{CO}_{2}$ capture using mesoporous $\mathrm{TiO}_{2} /$ graphene oxide nanocomposites," Chemical Engineering Journal, vol. 263, pp. 374-384, 2015.

[187] J. Wang, X. Mei, L. Huang et al., "Synthesis of layered double hydroxides/graphene oxide nanocomposite as a novel high- 
temperature $\mathrm{CO}_{2}$ adsorbent," Journal of Energy Chemistry, vol. 24, no. 2, pp. 127-137, 2015.

[188] Y. Zhao, H. Ding, and Q. Zhong, "Synthesis and characterization of MOF-aminated graphite oxide composites for $\mathrm{CO}_{2}$ capture," Applied Surface Science, vol. 284, no. 1, pp. 138-144, 2013.

[189] Y. Cao, Y. Zhao, Z. Lv, F. Song, and Q. Zhong, "Preparation and enhanced $\mathrm{CO}_{2}$ adsorption capacity of $\mathrm{UiO}-66 /$ graphene oxide composites," Journal of Industrial and Engineering Chemistry, vol. 27, pp. 102-107, 2015.

[190] S. Pourebrahimi, M. Kazemeini, E. Ganji Babakhani, and A. Taheri, "Removal of the $\mathrm{CO}_{2}$ from flue gas utilizing hybrid composite adsorbent MIL-53(Al)/GNP metal-organic framework," Microporous and Mesoporous Materials, vol. 218, pp. 144-152, 2015.

[191] M. Mohamedali, D. Nath, H. Ibrahim, and A. Henni, "Review of recent developments in $\mathrm{CO}_{2}$ capture using solid materials: metal organic frameworks (MOFs)," Intech Open, vol. 6, pp. 115-154, 2010.

[192] R. A. Fiuza, R. Medeiros de Jesus Neto, L. B. Correia, and H. M. Carvalho Andrade, "Preparation of granular activated carbons from yellow mombin fruit stones for $\mathrm{CO}_{2}$ adsorption," Journal of Environmental Management, vol. 161, pp. 198-205, 2015.

[193] E. David and J. Kopac, "Activated carbons derived from residual biomass pyrolysis and their $\mathrm{CO}_{2}$ adsorption capacity," Journal of Analytical and Applied Pyrolysis, vol. 110, pp. 322-332, 2014.

[194] F. Montagnaro, A. Silvestre-Albero, J. Silvestre-Albero et al., "Post-combustion $\mathrm{CO}_{2}$ adsorption on activated carbons with different textural properties," Microporous and Mesoporous Materials, vol. 209, pp. 157-164, 2015.

[195] M. Erto, M. Pellerano, and A. Delebarre, "Pressure swing adsorption for $\mathrm{CO}_{2} / \mathrm{N}_{2}$ and $\mathrm{CO}_{2} / \mathrm{CH}_{4}$ separation: comparison between activated carbons and zeolites performances," Fuel Processing Technology, vol. 138, pp. 271-283, 2015.

[196] D. Xu, P. Xiao, J. Zhang et al., "Effects of water vapour on $\mathrm{CO}_{2}$ capture with vacuum swing adsorption using activated carbon," Chemical Engineering Journal, vol. 230, pp. 64-72, 2013.

[197] G. Sethia and A. Sayari, "Comprehensive study of ultramicroporous nitrogen-doped activated carbon for $\mathrm{CO}_{2}$ capture," Carbon, vol. 93, pp. 68-80, 2015.

[198] N. Díez, P. Álvarez, M. Granda, C. Blanco, R. Santamaría, and R. Menéndez, " $\mathrm{CO}_{2}$ adsorption capacity and kinetics in nitrogen-enriched activated carbon fibers prepared by different methods," Chemical Engineering Journal, vol. 281, no. 1, pp. 704-712, 2015.

[199] R.-L. Tseng, F.-C Wu, and R.-S. Juang, “Adsorption of $\mathrm{CO}_{2}$ at atmospheric pressure on activated carbons prepared from melamine-modified phenol-formaldehyde resins," Separation and Purification Technology, vol. 140, pp. 53-60, 2015.

[200] A. Houshmand, M. S. Shafeeyan, A. Arami-Niya, and W. M. A. W. Daud, "Anchoring a halogenated amine on the surface of a microporous activated carbon for carbon dioxide capture," Journal of the Taiwan Institute of Chemical Engineers, vol. 44, no. 5, pp. 774-779, 2013.

[201] M. J. Mostazo-López, R. Ruiz-Rosas, E. Morallón, and D. Cazorla-Amorós, "Generation of nitrogen functionalities on activated carbons by amidation reactions and Hofmann rearrangement: chemical and electrochemical characterization," Carbon, vol. 91, pp. 252-265, 2015.

[202] J. A. A. Gibson, A. V. Gromov, S. Brandani, and E. E. B. Campbell, "The effect of pore structure on the $\mathrm{CO} 2$ adsorption efficiency of polyamine impregnated porous carbons," Microporous and Mesoporous Materials, vol. 208, pp. 129-139, 2015.

[203] M. S. Shafeeyan, W. M. A. W. Daud, A. Shamiri, and N. Aghamohammadi, "Adsorption equilibrium of carbon dioxide on ammonia-modified activated carbon," Chemical Engineering Research and Design, vol. 104, pp. 42-52, 2015.

[204] Q. Liu, Y. Shi, S. Zheng et al., "Amine-functionalized lowcost industrial grade multi-walled carbon nanotubes for the capture of carbon dioxide," Journal of Energy Chemistry, vol. 23, no. 1, pp. 111-118, 2014.

[205] M.-S. Lee and S.-J. Park, "Silica-coated multi-walled carbon nanotubes impregnated with polyethyleneimine for carbon dioxide capture under the flue gas condition," Journal of Solid State Chemistry, vol. 226, pp. 17-23, 2015.

[206] M.-S. Lee, S.-Y. Lee, and S.-J. Park, "Preparation and characterization of multi-walled carbon nanotubes impregnated with polyethyleneimine for carbon dioxide capture," International Journal of Hydrogen Energy, vol. 40, no. 8, pp. 3415-3421, 2015.

[207] F. Su, C. Lu, W. Cnen, H. Bai, and J. F. Hwang, "Capture of $\mathrm{CO}_{2}$ from flue gas via multiwalled carbon nanotubes," Science of The Total Environment, vol. 407, no. 8, pp. 3017-3023, 2009.

[208] A. Kumar Mishra and S. Ramaprabhu, "Polyaniline/multiwalled carbon nanotubes nanocomposite-an excellent reversible CO2 capture candidate," RSC Advances, vol. 2, no. 5, pp. 1746-1750, 2012.

[209] M. M. Gui, Y. X. Yap, S.-P. Chai, and A. R. Mohamed, "Multi-walled carbon nanotubes modified with (3-aminopropyl)triethoxysilane for effective carbon dioxide adsorption," International Journal of Greenhouse Gas Control, vol. 14, pp. 65-73, 2013.

[210] Y. G. Ko, H. J. Lee, H. C. Oh, and U. S. Choi, "Amines immobilized double-walled silica nanotubes for $\mathrm{CO}_{2}$ capture," Journal of Hazardous Materials, vol. 250-251, no. 251, pp. 53-60, 2013. 